

\section{Sumário}

I. Direito À Saúde e Políticas. 13

As Redes de Atenção à Saúde nos 30 anos do Sistema Único de Saúde: histórias, PROPOSTAS E DESAFIOS

Márcia Araújo Sabino de Freitas e Maria Rizoneide Negreiros de Araújo

DiREITO À SAÚdE PARA O RESIDENTE FRONTEIRIÇO: DESAFIO PARA A INTEGRALIDADE DO SUS .35 Fabrícia Helena Linhares Coelho da Silva Pereira, Livia Maria de Sousa e Tarin Cristino Frota Mont Alverne

Medidas provisórias e políticas públicas: Uma análise do PaPEl do Congresso NaCiOnal NAS POlíticas de SAÚde nO GOVERno Dilma $(2011-2016)$............................................55

Clóvis Alberto Bertolini de Pinho

Os LIMITES E A EXTENSÃo DA DEFESA DE DIREITOS FUNDAMENTAIS POR MEIO DE INSTRUMENTOS PROCESSUAIS DE COGNIÇÃo ESTREITA: MANDAdO DE SEGURANÇA E O CASO DA SAÚDE ...............76 Héctor Valverde Santana e Roberto Freitas Filho

DESENHANdo MOdElos de SISTEMAS de DISPUTAS PARA A ADMINISTRAÇÃo PÚbliCA: PROPOSIÇÕES ACERCA DA POLÍTICA PÚBLICA DE FORNECIMENTO DE MEDICAMENTOS PELO VIÉS DO DIÁLOGO INSTITUCIONAL

Mônica Teresa Costa Sousa e Maíra Lopes de Castro

O ACCOUNTABILITY DO SERVIÇO PÚBlico DE SAÚdE E A ATUAÇÃo INSTITUCIONAL NO ESTADO DO CEARÁ. 125 Mariana Dionísio de Andrade, Beatriz de Castro Rosa e Eduardo Régis Girão de Castro Pinto

Privacidade Relacional no ambulatório de oncogenética do hospital de Clínicas de Porto Alegre 146

Leonardo Stoll de Morais, Patrícia Ashton-Prolla, José Roberto Goldim e Márcia Santana Fernandes

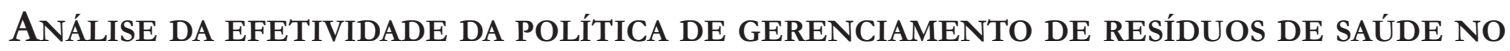
Município de SANTOS 175

Renato Braz Mehanna Khamis, Lígia Maria Comis Dutra e Thays Costa Nostre Teixeira

II. Direito À Saúde e Judicialização

Atuação da Defensoria Pública para a garantia do direito à saúde: A judicialização COMO INSTRUMENTO DE ACESSO À SAÚDE 195 Ramiro Nóbrega Sant'Ana 
A Judicialização do aCesso aos medicamentos em Belo Horizonte: UMA QUESTão sobre EQUIDADE.

Kammilla Éric Guerra de Araújo e Carlota Quintal

THE COURTS AND THE DELIVERY OF MEDICINES BY UNIFIED HEALTH SYSTEM IN BRAZIL: RECENT DEVELOPMENTS IN A DIFFICULT RELATIONSHIP BETWEEN JUDGES AND POLICY-MAKERS. 237 Eduardo Rocha Dias e Gina Vidal Marcílio Pompeu

Direito, SAÚde E SUICÍDIO: IMPACTOS DAS LEIS E DECISÕES JUDiCiAIS NA SAÚdE DOS JOVENS LGBT

Bruno Rafael Silva Nogueira Barbosa e Robson Antão de Medeiros

A Desproteção À SAÚde do TRABALHAdor e SUA JUdicialização Renata Salgado Leme e Luiz Pinto de Paula Filho

A judicialização da saúde sob o olhar da Análise Econômica do Direito: um exame dos INCENTIVOS AO AJUIZAMENTO E À SOLUÇÃo EXTRAJUdiCiAL DE CONFLITOS ..........................308 Victor Aguiar de Carvalho

III. Direito À SAúde e as Instituições de REgulação

A regulação da saúde Suplementar no Brasil: Perspectivas e ameaÇaS 329 Carlos Marden Cabral Coutinho e Taís Vasconcelos Cidrão

Os Mecanismos de Participação da Agência Nacional de Saúde Suplementar (ANS)343 Natasha Schmitt Caccia Salinas e Fernanda Martins

Papel institucional dos canais de reclamação para a Resolução extrajudicial de CONFLITOS SOBRE PLANOS DE SAÚDE: UMA ANÁLISE COMPARADA

Rafaela Magalhães Nogueira Carvalho, Antônio José Maristrello Porto e Bruno Araujo Ramalho

MedicAmentos SEM REgistros NA ANVISA: UMA ABORDAGEM INSTITUCIONAL .395 Igor De Lazari, Sergio Dias e Carlos Bolonha

A SUSTENTABILIDADE ECONÔMICO-FINANCEIRA DAS OPERADORAS DE PLANOS DE SAÚDE DIANTE DA CONCESSÃo INDISCRIMINADA DE TUTELAS DE URGÊNCIA NO BRASIL. 410 Álisson José Maia Melo e Nathalia Aparecida Sousa Dantas

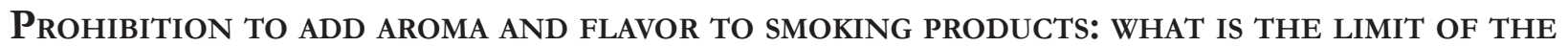
Regulatory power of the Brazilian Health Regulatory Agency? 435 Joedson de Souza Delgado e Ivo Teixeira Gico Júnior 


\title{
Os limites e a extensão da defesa de direitos fundamentais por meio de instrumentos processuais de cognição estreita: mandado de segurança e o caso da saúde*
}

\author{
Civil rights enforcement through limited \\ cognition procedural tools, limits and \\ extention: writ of mandamus and the health \\ rights case
}

Héctor Valverde Santana**

Roberto Freitas Filho***

\section{Resumo}

O objetivo deste artigo é analisar os limites da defesa de direitos fundamentais por meio de mandado de segurança no Tribunal de Justiça do Distrito Federal e Territórios. Postula-se que o caso seja exemplar de um tipo de atividade processual e de padrão decisório que tem repercussões no campo da justiça coletiva e da administração pública. Propõe-se que a intervenção judicial na atividade do Poder Executivo no caso da saúde deve distinguir quatro situações possíveis. A intervenção judicial na política pública da saúde pode se dar pela ausência de prestação do direito, havendo regra específica que o preveja, ou seja, a regra existe e não é cumprida; ou quando a regra aplicável é inválida, pois é compreendida como insuficiente a dar mínima efetividade ao direito fundamental em face de uma regra de hierarquia superior reconhecida como contrária a ela; ou diante da ausência de regra específica que preveja o direito vindicado (caso de analogia normativa), não havendo regra aplicável ao caso; ou pela ausência de política pública que preveja como direitos enunciados de forma abstrata na Constituição Federal devem ser fruídos, não havendo uma política pública aplicável ao caso, apenas a enunciação genérica constitucional da existência do direito. É apresentada a visão liberal de Ronald Dworkin acerca da questão da igualdade na fruição de direitos prestacionais. Mostra-se a dificuldade de formulação de critérios para a identificação do sentido de dever jurídico originário em relação ao caso em análise e aborda-se a ideia de justiça coletiva, as visões caritativas e pietativa sobre o Direito, sugerindo-se que essas últimas não são adequadas à reflexão sobre problemas de alocação individual de recursos coletivos.

Palavras-chave: Políticas públicas. Saúde. Intervenção judicial. Mandado de segurança.

** Doutor em Direito (PUC/SP), Professor do Programa de Pós-graduação stricto sensu do Centro Universitário de Brasília (UniCEUB), Juiz de Direito Substituto de Segundo Grau do TJDFT. E-mail: hectorvsantana@gmail.com.
*** Doutor em Direito (USP), Professor do Programa de Mestrado do IDP. Desembargador do TJDFT. E-mail: freitasfilho.roberto@ gmail.com.
Recebido em 27/08/2018

Aprovado em 18/09/2018$$
\text { gmail.com. }
$$ 


\section{Abstract}

The purpose of this article is to analyze the limits of the defense of fundamental rights through writ of mandamus in the Federal District Court and Territories. It is suggested that the case is exemplary of a type of procedural strategy and decision-making process that has implications in the field of collective justice and public administration. It is proposed that judicial intervention in the activity of the Executive Branch in the case of health should distinguish and take into account four possible situations. Judicial intervention in public health policy in the absence of any statutory provision, with a specific rule that provides for it, ie, the rule exists and is not enforced; or when the applicable rule is invalid, since it is insufficient to give basic fundamental effectiveness to the right in the face of a rule of superior hierarchy recognized as contrary to it; or in the absence of a specific rule that provides for any vindicated right (case of normative analogy), with no rule applicable to the case; or by the absence of public policy that provides for effectiveness, merely stated as rights enunciated abstractly in the Federal Constitution, there being no public policy applicable to the case, only the generic constitutional claim. Ronald Dworkin's liberal vision of the issue is suggested to be an adequate theoretic approach to the case. It shows the difficulty of formulating criteria for establishing precise meaning of a given legal obligation in relation to the case under analysis and approaches the idea of collective justice, the charitable and pitiful visions about the Law, suggesting that the later are not adequate approaches to deal with problems of individual allocation of collective resources.

Key words: Public policy. Health. Judicial activism. Writ of Mandamus.

\section{INTRODUÇÃo}

Argumenta-se, no presente artigo, que tratar problemas relativos a políticas públicas, as quais devem racionalizar a alocação de recursos coletivos, por meio de instrumentos processuais em que a cognição é estreita, resulta em problemas conceituais e sistêmicos, em escala transindividual, geradores de graves disfuncionalidades jurídicas, ou seja, nos termos do próprio Direito, os instrumentos processuais de cognição restrita promovem injustiças. A ausência de correta interpretação jurídica agrava a compreensão do sentido e alcance de textos normativos que criam direitos de forma genérica. Dentre outros problemas, a ideia de igualdade, reguladora da discussão jurídica sobre a justiça desses casos, resta comprometida.

Há um padrão de atuação processual de advogados, ao qual corresponde um padrão decisório dos Tribunais, segundo o qual são ajuizados mandados de segurança individuais para a fruição de direitos considerados públicos subjetivos como de medicamentos e de tratamentos médicos não previstos em regras específicas, tanto das leis que tratam desse tema quanto das normas infraconstitucionais, especialmente as normas de regulação do Sistema Único de Saúde e da Agência Nacional de Saúde Suplementar, nos quais, em geral, no mérito, os topoi da discussão orbitam a natureza constitucional do direito à saúde, a dramaticidade da situação de saúde do impetrante e, consequentemente, a possível melhora se for concedido o pedido, além da tragicidade da saúde no Brasil. A respeito do aspecto processual, a discussão, no âmbito de instrumentos processuais como os mandados de segurança, transita nos campos da existência ou não de direito líquido e certo, da legitimidade passiva do agente impetrado e da urgência da medida a ser concedida.

Em uma medida significativa, no pano de fundo do diálogo sobre o direito à saúde, se estabelecem disputas retóricas sobre a justiça como caridade, sobre a justiça formal e sobre o funcionamento das políticas públicas, embora nem sempre esses argumentos sejam veiculados de forma expressa nos votos.

O objetivo do presente trabalho é refletir sobre os limites da atuação do Poder Judiciário nas políticas públicas, por definição compostas de séries decisórias condicionadas normativamente e efetivadas mediante articulação multi e interinstitucional. Para isso, o caso específico dos mandados de segurança em saúde, 
propostos no Tribunal de Justiça do Distrito Federal e Territórios, servirão de situação exemplar, assumida essa instância como representativa de padrão decisório mais amplo, talvez do próprio Poder Judiciário como um todo.

\section{Políticas PÚblicas: algumas Considerações}

As políticas públicas se constituem no modo pelo qual a comunidade política decide, coletivamente, organizar a oferta e o modo de fruição de direitos que são limitados pela necessidade de se estabelecer critérios sobre a alocação de recursos orçamentários destinados a determinada prioridade normativa. Além disso, em geral, trata-se de direitos de natureza prestacional, ou seja, aqueles que dependem de ação específica do Estado no sentido de prover instalações, serviços, produtos e ações direcionadas a sua efetivação.

As normas jurídicas instituidoras de direitos sociais, portanto carentes de políticas públicas para a sua fruição, possuem características de finalidade e funcionalidade que tornam particularmente complexa sua aplicação, dentre as quais: 1 . dizem respeito a direitos que não são apropriáveis individualmente em uma episteme liberal, enquanto direitos subjetivos; 2. sua produção de efeitos é apreciada de forma distinta do modelo tradicional, ou seja, são normas que pedem efetividade, não somente eficácia. Pretendem, assim, intervenção na realidade social de forma que sejam atingidas finalidades coletivamente relevantes como redução de desigualdades, diminuição da pobreza, proteção de grupos sociais vulneráveis e oferta adequada e universal de serviços essenciais. ${ }^{1}$

Há uma relação necessária, portanto, entre o modo por meio do qual se elege socialmente o tema, os objetivos e a forma de efetivação de uma determinada política, e o direito, instância que lhe vai conferir o modo formalmente imperativo pelo qual ela se realizará. Haverá, assim, normas de diversos tipos (de execução, fiscais, processuais, materiais, dentre outros), que dão forma e operabilidade à política pública. ${ }^{2}$

Em perspectiva funcional, uma política pública é um complexo de decisões inter e multi-institucional nas quais são selecionadas ações que objetivam fortalecer ou modificar um estado de coisas da realidade social, por meio de estratégias de atuação e de alocação de recursos para a consecução dos objetivos desejados. ${ }^{3}$

Trata-se, portanto, de forma predominante, de modelos de ação do Estado que envolvem recursos de toda a comunidade política, cuja alocação pode se dar de maneira individual em termos de quantificação de custo, no caso de direitos em que as prestações específicas sejam monetizáveis. Nesse sentido, são recursos que podem ser apropriados de maneira uti singuli, sem que a natureza coletiva dos mesmos seja infirmada. Ao se conceder um determinado medicamento (direito à saúde), uma vaga em creche (direito à educação), o direito a obter financiamento para a compra de casa própria a juros subsidiados (direito à moradia), por exemplo, é possível quantificar individualmente o custo financeiro dessa medida.

Neste artigo aparece um problema decisório importante quando se pensa em decisões racionais sobre alocação de recursos escassos, segundo certas premissas de justiça e eficiência. A questão é que, claramente, os custos de fruição são suportados por todos, não havendo a possibilidade de uma solução sem impacto financeiro. Não haveria qualquer problema jurídico relevante se, do ponto de vista econômico, fosse possível prover vagas em escolas e hospitais de elite para todos aqueles que necessitassem ou desejassem deles fazer

1 FREITAS FILHO, Roberto et al. Políticas públicas e protagonismo judicial no STF: relatório de pesquisa do grupo de estudo e pesquisa em políticas públicas e hermenêutica. Disponível em: <https://www.publicacoesacademicas.uniceub.br/jus/article/ view/1503>. Acesso em: 24 jun. 2018.

2 BUCCI, Maria Paula Dallari. O conceito de política pública em direito. In: (Org.). Políticas públicas: reflexões sobre o conceito jurídico. São Paulo: Saraiva, 2006. p. 37.

3 SARAVIA, Enrique. Introdução à teoria da política pública. In: FERRAREZI, Elisabete; SARAVIA, Enrique. Políticas públicas: coletânea. Brasília: ENAP, 2006. p. 29. 
uso. A vida, a realidade físico-material na qual todos existimos, entretanto, não é assim. A realidade é que nem todos podem ser internados nos melhores hospitais disponíveis, nem todos podem ter acesso às melhores universidades disponíveis, assim como também nem todos podem ter acesso aos melhores tratamentos médicos do mundo. Tem-se, portanto, escassez, em vários sentidos, já que há diversos tipos de limites materiais, derivados tanto de escolhas políticas quanto da própria natureza das coisas, que impedem o acesso irrestrito de todos a tudo. Deve-se, portanto, fazer escolhas, as quais se espera sejam racionais e regradas.

As decisões do Poder Judiciário, no caso em que se lida com regras de funcionamento de políticas públicas, podem promover controle sobre a sua legalidade ou, em alguns casos, mesmo resultar em intervenção na formulação e no funcionamento dos sistemas de decisões que as tornam efetivas. Portanto, nas políticas públicas, é necessário distinguir quatro diferentes tipos de situação nas quais se leva ao Poder Judiciário a análise: 1. as regras existem e uma ou mais não é cumprida; 2. a regra aplicável ao caso é inválida, pois seria insuficiente dar mínima efetividade ao direito fundamental a qual se refere; 3. não há uma regra aplicável ao caso específico, mesmo havendo política pública sobre o tema determinado; 4. não há uma política pública, com marco normativo infraconstitucional que a estruturasse, aplicável ao caso, apenas a enunciação genérica constitucional da existência do direito.

A rigor, apenas na hipótese "1", o controle judicial de políticas públicas se dá sem a constituição de regra nova. Ou seja, no primeiro caso, há uma nítida separação entre o que o Poder Judiciário faz e o que o Poder Executivo e o Poder Legislativo fazem, já que se trata de decidir sobre o inadimplemento de um direito previsto, tanto na sua enunciação genérica constitucional quanto nas condições objetivas previstas nas normas infraconstitucionais.

Nas demais hipóteses, há verdadeira participação do Poder Judiciário na regulação do campo de relações determinado, no sentido de que ele faz regra que constitui o marco normativo que trata daquele setor. Quando se estende um direito para além das hipóteses previstas como limites em um determinado marco regulatório, na verdade se está alterando esse mesmo marco regulatório, estabelecendo novas expectativas gerais dos destinatários das normas, em relação ao que significam os direitos lá previstos. ${ }^{4}$

Admitida a premissa de que há uma nova regra que integrará o sistema de regras daquele campo específico, há que se lidar com o problema de que, sendo direitos sobre os quais há limites materiais de toda ordem, alterar-se-á a forma de alocação de recursos e a isonomia na sua fruição. Ou seja, ao julgar se imiscuindo na política pública que organiza, normativamente, a forma por meio da qual se efetiva um direito, haverá consequências empíricas que deverão estar consideradas no processo de formação da decisão. ${ }^{5}$

A questão dos impactos das decisões jurídicas no mundo fático é um problema tão importante na reflexão sobre o modo como se decide, que a Lei de Introdução às Normas do Direito Brasileiro (LINDB) sofreu recente alteração, com a introdução da determinação de que as consequências devam ser consideradas. Como exemplo, a Lei n. 13.655/2018, dentre outras novidades, procedeu à introdução do art. 20 à LINDB, norma que determina: "Nas esferas administrativa, controladora e judicial, não se decidirá com base em valores jurídicos abstratos sem que sejam consideradas as conseqüências práticas da decisão. " Aqui surge uma questão central da presente reflexão. Por tudo o que se disse sobre as políticas públicas que envolvem direitos prestacionais e os problemas consequencialistas de toda ordem que a intervenção judicial nas políticas públicas ensejam, mostra-se impossível considerar, adequadamente, no processo decisório, os impactos dessas decisões em instrumentos processuais de cognição estreita, como é o caso do mandado de segurança.

Há três dimensões de análise das questões judicializadas relativas às políticas públicas que envolvem alo-

4 Em um sentido que tangencia o argumento, cf. (BARROSO, Luís Roberto. Da falta de efetividade à judicialização excessiva: direito à saúde, fornecimento gratuito de medicamentos e parâmetros para a atuação judicial. In: PEREIRA NETO, Cláudio; SARMENTO, Daniel (Org). Direitos sociais: fundamentos, judicialização e direitos sociais em espécie. Rio de Janeiro: Lumen Juris, 2008.). 5 WANG, Daniel Wei Liang. Escassez de recursos, custos dos direitos e reserva do possível na jurisprudência do STF. In: SARLET, Ingo Wolfgang; TIMM, Luciano Benetti (Org.). Direitos fundamentais: orçamento e "reserva do possível". 2. ed. Porto Alegre: Livraria do Advogado, 2010. p. 351. 
cação individual de recursos coletivos que podem ajudar a reflexão sobre o problema, considerada a prática judicante atual sobre o tema: 1 . no plano econômico, é necessário considerar de maneira séria a ideia de que as escolhas econômicas (mas não exclusivamente elas) são sempre trágicas e, portanto, demandam avaliações consequencialistas; 2 . no plano teórico, é preciso enfrentar um argumento no qual aparece uma noção difusa, que se apresenta totalmente equivocada, da adoção de uma possível oposição entre os princípios do resgate e do seguro prudente, cunhados por Ronald Dworkin; 3. no plano político, a consideração da ideia de igualdade perante as regras legais, princípio de um estado democrático de direito, o que deve excluir da racionalidade jurídica a piedade, a caridade e a questão psicológica do sentimento de culpa.

Como é nítido, há uma enorme complexidade na formulação, implementação e avaliação das políticas públicas, o que torna central a questão do estabelecimento de consensos conceituais e hermenêuticos sobre os limites, as possibilidades e o alcance da prestação de direitos a ela submetidos. Decidir sobre políticas públicas de modo a nela intervir e reformular esses limites, possibilidades e alcance pode ser gravemente danoso à sua funcionalidade sistêmica e pode gerar injustiças na forma de tratamentos aleatoriamente diferenciados de toda sorte e ineficiências alocativas e de fruição.

A título exemplar, o caso do direito à saúde é especialmente sensível, pois a política a ele relacionada possui complexidades adicionais e específicas em relação a outras, como a de educação. Respeitando-se o limite próprio da síntese imposta por uma reflexão como a que ora se faz, destaque-se apenas o fato de que há dois sistemas de prestação de serviços de saúde, público e privado; três níveis de governo nos quais a política funciona, enormes pressões de grupos de interesses funcionando como atores no cenário de discussões sobre o tema (por exemplo, a indústria farmacêutica e as associações de portadores de doenças raras), relações comerciais globais envolvidas (por exemplo, o problema da chamada "quebra de patentes"), além de encetar, como tema, um feixe de valores e sensibilidades, sobretudo, como já mencionado, de natureza psicológica, potencialmente bloqueadores de fórmulas discursivas minimamente racionais no processo de tomada de decisão.

Dadas as características das políticas públicas e do direito à saúde, alguns parâmetros de consideração das questões jurídicas a ela relacionadas parecem se colocar como condição de possibilidade de discussão racional. É nítida a necessidade de considerar o direito à saúde como tendo um objeto sujeito a limites materiais de escassez, o que entreabre a necessária consideração transindividual do problema. Dito de outra forma, o problema do direito à saúde não pode ser compreendido somente com base na noção de um direito subjetivo oponível contra todos, ao modo fiat justitia et ruat caelum.

Os conflitos dessa natureza aparecem na dimensão individual, porém, na realidade são problemas coletivos. São lides entre partes limitadas e com objeto definido, como uma pretensão resistida resultante de um dissenso entre Caio e Tício, na forma da tradicional doutrina jurídica. Pode assumir a forma de um pretenso direito enunciado na Constituição Federal ou disposto em um contrato entre uma empresa e um consumidor. Ocorre que, na sociedade de massas e no marco do constitucionalismo social, a recorrência desse tipo de conflito indica a existência de classes, grupos e categorias de titulares de direito que, em conjunto, são alcançados potencialmente pelas decisões. ${ }^{6}$ Esses problemas são, em sua essência, transindividuais, apesar de serem levados ao Poder Judiciário como interindividuais. São questões que pedem soluções baseadas na ideia de justiça enquanto distributividade, não como comutatividade.

Um argumento às vezes utilizado para justificar decisões de concessão de direitos com base em normas constitucionais genéricas é o de que o Poder Judiciário estaria cumprindo o seu papel de forçar a concretização dos direitos fundamentais. Ocorre que, nesses casos, se trata de um problema de justiça distributiva, que diz respeito à alocação ou apropriação individual de recursos comuns e um sistema jurídico que não seja capaz de regular de forma racional e justa essa distribuição erode sua própria legitimidade. Em outras palavras,

6 LOPES, José Reinaldo de L. Justiça e poder judiciário ou a virtude confronta a instituição. In: Direitos Sociais: teoria e prática. São Paulo: Método, 2006. p. 121. 
a sensação de aleatoriedade decisória, de instabilidade semântica das normas e de carência de fundamentos sensatos ou parâmetros decisórios comensuráveis leva à percepção de que o Poder Judiciário é somente mais um campo de luta política por direitos, em vez de ser o fiador da legalidade e da justiça formal enquanto a busca de decisões isonômicas. Mesmo que esse seja um resultado indesejado da incapacidade dos órgãos estritamente políticos (Parlamento e Executivo) de responderem às demandas sociais mais prementes, talvez seja o caso do exercício judicial da auto-contenção, em nome da manutenção das condições de legitimidade.

\section{O CASO EXEMPLAR}

No presente tópico do artigo, far-se-á a apresentação de um caso exemplar, julgado no âmbito de uma das Câmaras Cíveis do Tribunal de Justiça do Distrito Federal e Territórios. Para efeito do argumento central apresentado neste artigo, não há necessidade de exposição do nome da parte interessada, bem como informações que possam identificá-la ao longo do texto. Assim, mesmo sendo públicas as informações, tendo em vista não haver restrições relativas às hipóteses de segredo de justiça, há opção pela preservação da identidade da parte, evitando-se, assim, exposição desnecessária. As demais informações relevantes à compreensão dos aspectos fáticos que delineiam o caso serão expostas. Feita essa consideração metodológica, passa-se à exposição do caso. ${ }^{7}$

Trata-se de um mandado de segurança impetrado contra o Secretário de Estado de Saúde do Distrito Federal, a Diretora Presidente da Fundação Hemocentro de Brasília e o Distrito Federal, no qual se pleiteia que o Distrito Federal seja compelido a conceder medicamento que não se encontra padronizado, ou seja, não está normatizado como de necessário fornecimento.

O interessado impetrou mandado de segurança contra o que considerou omissão do Secretário de Estado de Saúde do Distrito Federal e da Diretora-Presidente da Fundação Hemocentro de Brasília. Ele, por ser hemofílico (hemofilia B grave, CID: D67.0), pretendeu que as autoridades apontadas como coatoras fornecessem 50.000 UI do concentrado de fator IX recombinante. A medicação foi prescrita por médica do Núcleo de Coagulopatia de Hemoterapia, do Hospital Regional da Asa Norte - HRAN, pertencente à rede pública. A referida médica prefere medicações de origem recombinante, que, por não possuírem proteínas humanas ou animais, não transmitem doenças. Os fatores de coagulação derivados de sangue humano, em sua opinião, apresentam risco de transmissão de agentes patógenos. Ainda segundo ela, os consensos mundiais recomendam o concentrado de fator IX recombinante, já oferecido pela rede pública para os portadores de hemofilia A.

A Relatora do mandado de segurança no Tribunal de Justiça do Distrito Federal e Territórios deferiu a medida liminar. O Ministro Ricardo Lewandowski, porém, suspendeu parte da execução da decisão (efeito suspensivo liminar em pedido de suspensão de segurança, art. 15, \ $4^{\circ}$, da Lei n. 12.016/2009), determinando que o tratamento fosse prestado conforme o protocolo do Ministério da Saúde.

Terapia diversa somente poderia ser prestada se a necessidade fosse comprovada por junta médica oficial. Nas razões da decisão de suspensão, o Ministro observou que o Supremo Tribunal Federal reconheceu a repercussão geral dos temas relativos à obrigatoriedade do Estado fornecer remédio de alto custo e de medicamento não registrado na Agência Nacional de Vigilância (ANVISA). As informações trazidas àquele momento indicavam que o tratamento oferecido pelo Sistema Único de Saúde (SUS) era adequado e suficiente. Ainda segundo o Ministro, não havia prova suficiente de que concentrado de fator IX recombinante fosse mais eficiente do que o concentrado de fator IX plasmático.

7 BRASIL. Tribunal de Justiça do Distrito Federal e Territórios. Primeira Câmara Cível. Mandado de Segurança. MSG - Mandado de Segurança 2016.00.2.022657-4. 
Segundo a Associação Brasileira de Hematologia, Hemoterapia e Terapia Celular, a Dra. Margareth Castro Ozelo, professora da Disciplina de Hematologia e Hemoterapia do Departamento de Clínica Médica da Faculdade de Ciências Médicas da Universidade Estadual de Campinas (Unicamp), e a Fundação Hemocentro de Brasília apoiam o Programa Nacional de Coagulopatias Hereditárias da Coordenação Geral de Sangue e Hemoderivados do Ministério da Saúde. O Ministro Ricardo Lewandowski registrou que o tratamento oferecido no Brasil é comparável ao dos países desenvolvidos e que as prescrições da médica vinculada ao Sistema de Saúde do Distrito Federal carecem de melhores evidências científicas, resultando em prejuízo ao erário.

Há dois aspectos importantes a registrar no presente caso: 1. que o concentrado de fator IX recombinante é adquirido pela Secretaria de Saúde do Distrito Federal somente para atender a ordens judiciais; 2. o custo do concentrado de longa duração é três vezes superior aos demais. ${ }^{8}$

Os concentrados de fator recombinantes são classificados em níveis de geração, de acordo com a existência de material biológico animal em seu conteúdo e sua meia-vida. A primeira e a segunda gerações contêm produtos biológicos de origem animal. A terceira geração eliminou materiais biológicos de origem animal do seu processamento. A quarta geração desenvolve-se com produtos de duração (meia vida) mais longa. ${ }^{9}$

A Diretora Presidente da Fundação Hemocentro, Dra. Miriam Daisy Calmon Scaggion, prestou informações. Segundo ela, o concentrado de fator IX recombinante não integra o programa de coagulopatias do Ministério da Saúde. Portanto, a aquisição é de responsabilidade da Secretaria de Estado de Saúde do Distrito Federal. A Fundação Hemocentro de Brasília não tem competência e orçamento para a aquisição desse medicamento. É responsável, apenas, pela dispensação. A Diretora informou, ainda, que enviou diversos ofícios aos órgãos responsáveis, cobrando a aquisição. ${ }^{10}$

O Distrito Federal ingressou no polo passivo. Formulou duas questões preliminares: ilegitimidade passiva e inadequação da via eleita. Quanto à primeira, sustentou a indicação errônea da autoridade. A atribuição para adquirir o concentrado de fator IX recombinante é da União. As secretarias estaduais apenas distribuem o medicamento (anexo I, d, da Portaria n. 204/GM/MS/2007, do Ministério da Saúde). Em relação à segunda preliminar, de inadequação da via eleita, o Distrito Federal defendeu a ausência de prova pré-constituída e a necessidade de prova pericial. Considerou insuficiente a documentação apresentada pelo impetrante. Na sua opinião, é controvertido que o concentrado de fator IX recombinante seja mais eficaz do que o oferecido pela rede pública, o plasmático.

Apenas uma médica defende o uso do recombinante, enquanto o plasmático compõe o protocolo clínico da política pública de saúde. Afirma que seria preciso prova pericial para comprovar a necessidade e a adequação do medicamento. Como o mandado de segurança requer prova pré-constituída, alegou que o feito deveria ser extinto. As principais alegações de mérito apresentadas pelo Distrito Federal podem ser esquematizadas da seguinte maneira: (1) o protocolo clínico do Ministério da Saúde é respaldado pela Federação Mundial de Hemofilia (FMH) e pela Organização Mundial de Saúde (OMS); (2) o protocolo clínico seguido pelo Distrito Federal recomenda a utilização do concentrado de fator IX plasmático (art. 19-M, da Lei n. 8.080/1990); (3) os concentrados recombinantes e plasmáticos possuem a mesma eficácia e são bastante seguros — não ocorre contaminação desde 1997; (4) os recombinantes de longa duração, também prescritos pela médica, possuem a mesma eficácia dos demais ${ }^{11}$

A Fundação Hemocentro de Brasília também prestou informações. Explicou que a profilaxia (caráter preventivo) é o tratamento padrão. Os concentrados de fatores de coagulação podem ser produzidos de duas maneiras: pelo fracionamento do plasma humano (produtos derivados do plasma humano) ou por

8 Informações constantes dos autos de mandado de segurança às folhas 159-168.

9 Informações constantes dos autos de mandado de segurança às folhas $86-89$.

10 Informações constantes dos autos de mandado de segurança às folhas 86 - 89.

11 Informações constantes dos autos de mandado de segurança às folhas 106-146. 
intermédio de técnicas de engenharia genética (produtos recombinantes). A eficácia é a mesma. A eficácia dos produtos recombinantes "normais" e de longa duração também é a mesma. Também ressaltou que a Federação Mundial de Hemofilia (FMH) e Organização Mundial de Saúde (OMS) não têm preferência por qualquer deles. ${ }^{12}$

O impetrante foi submetido à avaliação pela junta médica oficial, em razão da decisão do Presidente do Supremo Tribunal Federal proferida na suspensão de segurança. A junta médica oficial concluiu que é necessário aumentar a dose e a frequência do tratamento, mas não modificar o medicamento oferecido (f. 743, f. 757, f. 1276 e f. 771). Foi admitida a participação da Associação dos Voluntários, Pesquisadores e Portadores de Coagulopatias (AJUDE-C) como amicus curiae.

Esses foram os pontos relevantes do processo, permitindo já antecipar o problema que a via eleita enseja. Ou seja, o problema de o Poder Judiciário intervir em políticas públicas, especificamente naquelas de natureza prestacional, por meio de um instrumento processual de cognição estreita e imediata, caso do mandado de segurança.

\section{Mandado de Segurança e direito líquido e Certo}

O mandado de segurança exige a prova do direito líquido e certo, conforme arts. $5^{\circ}$, LXIX, da CF, e $1^{\circ}$, da Lei n. 12.016/2009. O Superior Tribunal de Justiça tem firme posicionamento no sentido de que a utilização do mandado de segurança para fornecimento de medicamentos está condicionada à existência de prova pré-constituída. Logo, o mandado de segurança não é cabível se houver necessidade de aprofundar o debate e produzir prova pericial. A jurisprudência tem entendido dessa forma. ${ }^{13}$

O ponto em foco na presente sessão é o de que as dificuldades já apontadas quanto à intervenção judicial nas políticas públicas, especialmente por meio de mandados de segurança, se evidenciam no âmbito do processo civil, em suas regras específicas de admissibilidade e de escopo de cognição. A ratio do mandado de segurança é a de um instrumento processual de cognição estreita e decisão rápida, em vista da natureza do direito alegadamente lesado e da existência de evidente direito, seja em sua existência quanto em sua extensão.

Embora alguns dos precedentes mencionados versem sobre laudos expedidos por médicos particulares, eles se aplicam ao caso em estudo. Todos eles concordam, em essência, que, se houver necessidade de dilação probatória, o mandado de segurança não será cabível. A prescrição trazida pelo impetrante, ainda que elaborada por médica da rede pública, não é absoluta. A ideia central que orienta e dá sentido ao instituto do regime de fé pública, que incide sobre os servidores públicos em alguns casos, não é a mesma que orienta e dá sentido ao que se convencionou chamar de observância do método científico, que se orienta por outras regras. O regime de fé pública aposta presunção de verdade ao que um determinado agente alega sobre algum fato, tendo em vista sua posição profissional de representar ou presentar o próprio Estado, em alguma medida. Trata-se, portanto, de uma presunção contrafática, normativa e institucional.

12 Informações constantes dos autos de mandado de segurança às folhas 150-151.

13 Cf. o seguinte apanhado de decisões: (RMS 47.265/RO, Rel. Ministro HUMBERTO MARTINS, SEGUNDA TURMA, julgado em 26/04/2016, DJe 09/05/2016); (AgRg no RMS 45.703/RO, Rel. Ministro BENEDITO GONÇALVES, PRIMEIRA TURMA, julgado em 12/05/2015, DJe 22/10/2015); (AgRg no RMS 46.373/RO, Rel. Ministro MAURO CAMPBELL MARQUES, SEGUNDA TURMA, julgado em 16/04/2015, DJe 23/04/2015); (RMS 28.962/MG, Rel. Ministro BENEDITO GONÇALVES, PRIMEIRA TURMA, julgado em 25/08/2009, DJe 03/09/2009 LEXSTJ vol. 242, p. 55); (AgRg no AgRg no AREsp 233.016/ CE, Rel. Ministro CASTRO MEIRA, SEGUNDA TURMA, julgado em 06/08/2013, DJe 16/08/2013); (REsp 1115417/MG, Rel. Ministro CASTRO MEIRA, SEGUNDA TURMA, julgado em 25/06/2013, DJe 05/08/2013); (RMS 30.746/MG, Rel. Ministro CASTRO MEIRA, SEGUNDA TURMA, julgado em 27/11/2012, DJe 06/12/2012); (AgRg no RMS 34.545/MG, Rel. Ministro BENEDITO GONÇALVES, PRIMEIRA TURMA, julgado em 14/02/2012, DJe 23/02/2012). 
Quanto à adoção do método científico, trata-se da busca de um consenso sobre a verdade a respeito de fatos, por meio de protocolos, estratégias de verificabilidade, comensurabilidade de resultados, além de avaliação dos impactos de alguma tecnologia no mundo fático. Nesse sentido, a adoção de um método científico para a tomada de decisão se impõe como um primeiro passo. Ou seja, como saber especulativo sobre os sentidos possíveis de princípios como justiça, eficiência, igualdade, dentre outros, o direito promove uma avaliação em perspectiva contrafática de condutas, processo que resulta em consensos normativos, mas que não prescindem de consensos empíricos prévios. Se não for possível estabelecer consensos prévios sobre a realidade como a asserção de que, por exemplo, um medicamento tem uma eficiência x por cento maior do que o outro, o direito se converte em puro decisionismo, em um vale-tudo hermenêutico. No caso em análise, a prescrição é questionada por outros profissionais da rede pública, tanto do Ministério da Saúde quanto da Fundação Hemocentro de Brasília, com base em critérios científicos, não de preferências.

As informações prestadas pela Fundação Hemocentro de Brasília e a manifestação do Distrito Federal no processo atestam que o tratamento dispensado pelo Sistema Único de Saúde é eficaz para o tratamento do impetrante. Como não há prova pré-constituída do direito líquido e certo, a via eleita é inadequada. Aqui não se trata de abordar o problema da eficácia ou não dos dois tipos de medicamentos, qual seria melhor ou não, mas se trata de reconhecer a dificuldade de verificar a existência de direito líquido e certo existente, em sua natureza e extensão.

Reconhecer que o impetrante não apresentou provas suficientes para a concessão da segurança não lhe representa prejuízo, na medida em que a via da ação ordinária lhe daria oportunidade de produzir prova necessária para o acolhimento do pedido. Com a instrução adequada, seria possível esclarecer as questões técnicas levantadas, impugnar os laudos produzidos e fornecer os subsídios necessários à decisão, a partir de critérios técnicos e de evidências científicas. A ação ordinária não representaria risco para a saúde do impetrante, já que há a possibilidade de concessão de tutela provisória, o que evita o risco de demora decorrente de dilação probatória.

A jurisprudência a respeito do direito à saúde indica que, embora seja um direito social, reconhece-se a faculdade da pessoa exigir do Estado prestações materiais que garantam efetivamente esse direito (exigibilidade frente ao Poder Público). Há, entretanto, como já dito, impacto das decisões judiciais nas políticas públicas no que toca à escassez de recursos, inexoráveis.

Reconhecendo a complexidade do tema, a Organização Mundial de Saúde constata que nenhum país conseguiu assegurar o acesso integral da população às tecnologias e intervenções de saúde, independentemente do grau de riqueza. A disponibilidade de recursos é um dos principais obstáculos para a cobertura universal, segundo o Relatório Mundial da Saúde produzido em 2010. ${ }^{14}$ Dentre as várias recomendações para a solução do problema, está a gestão eficiente dos recursos disponíveis: promover a eficiência e eliminar o desperdício. De acordo com o relatório, a atenção aos medicamentos pode reduzir, significativamente, as despesas, sem perda de qualidade, o que significa, dentre outras estratégias, utilizar opções mais baratas e igualmente eficazes, alternativamente aos medicamentos mais caros.

Em outra vertente, em relação à proteção individual do direito à saúde, a OMS adverte que, embora haja conclusões em andamento, investigadores verificaram, em alguns casos, que os mais pobres e vulneráveis se beneficiaram menos dessa busca ao Poder Judiciário, do que os mais ricos. No plano doutrinário, há algum consenso sobre os vários riscos da judicialização excessiva. Afirma-se que a falta de critérios e a adoção de decisões guiadas pela emoção põem em risco a continuidade das políticas de saúde pública, bem como que é errado supor que o problema se resume à colisão entre o direito à saúde e os princípios orçamentários.

Distintamente do argumento de que o direito à saúde seria apropriável como um direito público subjetivo, a chamada ponderação deveria considerar o dilema de se julgar entre o direito à vida e à saúde de uns

14 ORGANIZAÇÃO MUNDIAL DA SAÚDE -OMS. Relatório mundial da saúde 2010: financiamento dos sistemas de saúde. Disponível em: <http://www.who.int/eportuguese/publications/WHR2010.pdf>. Acesso em: 4 maio 2018. 
poucos contra o direito à vida e à saúde de muitos. ${ }^{15}$ Conforme já adiantado nas primeira sessões do texto, a doutrina faz referência a importantes questões como escassez de recursos, ausência de condições técnicas dos magistrados para gerir recursos, individualismo e decisões baseadas em critérios emocionais de compaixão e piedade..$^{16}$

\section{Fornecimento de medicamentos E ESTRUtURA NORMATIVA}

A complexidade do processo de definição do que seja o dever jurídico do Estado em prestar o direito à saúde não somente se expressa em relação aos contextos fático, econômico e político no qual se dá a adjudicação sobre o tema. $\mathrm{O}$ arcabouço normativo a respeito da assistência terapêutica e do fornecimento de medicamentos no Brasil é extremamente complexo e é expresso em uma cartografia de normas que vão desde a Constituição Federal; passando pela Lei n. 8.080/1990 (Lei do SUS); pela Lei n. 12.401/2011, que dispõe sobre a incorporação de tecnologia em saúde no âmbito do SUS; pelo Decreto n. 7.508/2011, que regulamenta a Lei do SUS; e pela Portaria GM n. 3.916/1998, que aprovou a Política Nacional de Medicamentos (PNM). Há uma série de outros dispositivos normativos relativos ao tema, tanto na esfera federal quanto nas esferas estadual e municipal, mas a espinha dorsal do sistema é formada por essas disposições.

O direito à saúde é garantido, na Constituição Federal, nos arts. $6^{\circ}$ e 196. O art. $6^{\circ}$ dispõe que a saúde é direito social, assim como a educação, a alimentação, o trabalho, a moradia, o transporte, o lazer, a segurança, a previdência social, a proteção à maternidade e à infância, a assistência aos desamparados. O art. 196 determina que a saúde é direito de todos e dever do Estado, garantido mediante políticas sociais e econômicas que visem à redução do risco de doença e de outros agravos e ao acesso universal e igualitário às ações e serviços para sua promoção, proteção e recuperação. A rede de ações e serviços públicos de saúde deve ser organizada com a participação da comunidade (art. 198, da CF).

Há dois pontos que devem ser destacados no art. 196, da CF, que condicionam o modo que o direito à saúde deve ser garantido: (1) a realização desse direito se dá mediante políticas sociais e econômicas e (2) o acesso deve ser universal e igualitário. O caráter social do direito à saúde tem como consequência o fato de que, embora ele possa ser garantido individualmente, sua realização se dá especialmente mediante políticas públicas que atinjam o maior número possível de pessoas, de modo igualitário. Há, portanto, uma dimensão coletiva nesse direito, cujos impactos não podem ser ignorados pelo operador jurídico e que supõem uma leitura jurídico-política-econômica dos limites e da extensão do sentido desse direito.

Há uma tensão dilemática na afirmação de que os direitos sociais apresentam uma dupla dimensão, uma dimensão subjetiva, que impede o Estado e terceiros de violá-los, e uma dimensão objetiva, que impõe ao Estado deveres legiferantes e de fornecer (executar) determinadas prestações aos cidadãos. Os direitos sociais tornam-se originários (direitos a prestações) quando o Estado tem o dever de criar condições para o exercício desses direitos ou quando se concede aos sujeitos a possibilidade de exigir prestações continuativas desses direitos. ${ }^{17}$ A tensão aparece como uma aparente contradição entre o direito à saúde não ser apenas de natureza programática e estar submetido a limites materiais e escolhas políticas para a sua fruição. Em se atribuindo à interpretação prevalência do sentido objetivo da norma que limita o direito à saúde, para alguns, estar-se-ia negando concretização a esses direitos. Há, nesses casos, o recurso aos topoi do risco de vida e do mínimo existencial. ${ }^{18}$

15 BARROSO, Luís Roberto. Da falta de efetividade à judicialização excessiva: direito à saúde, fornecimento gratuito de medicamentos e parâmetros para a atuação judicial. In: PEREIRA NETO, Cláudio; SARMENTO, Daniel (Org). Direitos sociais: fundamentos, judicialização e direitos sociais em espécie. Rio de Janeiro: Lumen Juris, 2008. p. 875-876.

16 SABINO, Marco Antonio da Costa. Saúde \& Judiciário: a atuação judicial: limites, excessos e remédios. Curitiba: Juruá, 2016. p. 126-142.

17 CANOTILHO, J.J. Gomes. Direito constitucional e teoria da constituição. 17. ed. Coimbra: Almedina. p. 477-478

18 SARLET, Ingo W. Comentário ao art. 196. In: CANOTILHO, J. J. Gomes (Coord.) et al. Comentários à constituição do Brasil. São Paulo: Saraiva/Almedina, 2013. p. $1.935-1.936$ 
As ações e serviços de saúde têm sua estrutura básica definida pela Lei n. 8.080/1990, que trata das condições para a promoção, proteção e recuperação da saúde, a organização e o funcionamento dos serviços correspondentes. O dever do Estado de garantir a saúde é delimitado pelo art. $2^{\circ}$ :

formulação e execução de políticas econômicas e sociais que visem à redução de riscos de doenças e de outros agravos e no estabelecimento de condições que assegurem acesso universal e igualitário às ações e aos serviços para a sua promoção, proteção e recuperação.

A Lei n. 12.401/2011 alterou a redação da Lei n. 8.080/1990, dispondo sobre a assistência terapêutica e a incorporação de tecnologia em saúde no âmbito do Sistema Único de Saúde. Segundo ela, a assistência terapêutica integral, prevista no art. 6, I, d, da Lei n. 8.080/1990, consiste em dispensação de medicamentos cuja prescrição esteja em conformidade com as diretrizes terapêuticas definidas em protocolo clínico e oferta de procedimentos terapêuticos constantes de tabelas elaboradas pelo gestor federal do Sistema Único de Saúde (art. 19-M, da Lei n. 8.080/1990)..$^{19}$

Os protocolos clínicos e as diretrizes terapêuticas deverão estabelecer os medicamentos ou produtos necessários nas diferentes fases evolutivas da doença, bem como aqueles indicados em casos de perda de eficácia e de surgimento de intolerância ou reação adversa. Os medicamentos serão avaliados quanto à sua eficácia, segurança, efetividade e custo-efetividade (art. 19-O, da Lei n. 8.080/1990).

$\mathrm{Na}$ falta de protocolo clínico, a dispensação será realizada com base nas relações de medicamentos instituídas pelo gestor federal do SUS e a responsabilidade pelo fornecimento será pactuada na Comissão Intergestores Tripartite. De forma suplementar, no âmbito de cada Estado e do Distrito Federal, com base nas relações de medicamentos instituídas pelos gestores estaduais do SUS e a responsabilidade pelo fornecimento será pactuada na Comissão Intergestores Bipartite. No âmbito de cada Município, também de forma suplementar, com base nas relações de medicamentos instituídas pelos gestores municipais do SUS. A responsabilidade pelo fornecimento, nesse caso, será pactuada no Conselho Municipal de Saúde (art. 19-P, da Lei n. 8.080/1990).

A incorporação, a exclusão ou a alteração de novos medicamentos, produtos e procedimentos, bem como a constituição ou a alteração de protocolo clínico ou de diretriz terapêutica, são atribuições do Ministério da Saúde, assessorado pela Comissão Nacional de Incorporação de Tecnologias no SUS (CONITEC), e serão efetuadas mediante a instauração de procedimento administrativo. O relatório da CONITEC levará em consideração (1) as evidências científicas sobre a eficácia, a acurácia, a efetividade e a segurança do medicamento; e (2) a avaliação econômica comparativa dos benefícios e dos custos em relação às tecnologias já incorporadas (arts. 19-P e 19-R, da Lei n. 8.080/1990). É vedada a utilização de medicamento e procedimento clínico ou cirúrgico experimental ou de uso não autorizado pela ANVISA ou sem registro (art. 19-T, da Lei n. 12.401/2011).

O requerimento de instauração do procedimento administrativo para a incorporação e a alteração pelo SUS de tecnologias em saúde e a constituição ou alteração de protocolos clínicos e diretrizes terapêuticas deverá ser acompanhado de evidência científica que demonstre que a tecnologia pautada é, no mínimo, tão eficaz e segura quanto aquelas disponíveis no SUS; e estudo de avaliação econômica comparando a tecnologia pautada com as tecnologias em saúde disponibilizadas no SUS (art. 15, do Decreto n. 7.646/2011).

A Relação Nacional de Medicamentos Essenciais (RENAME) é regulamentada pelos arts. 25 a 29, do Decreto n. 7.508/2011. Compreende a seleção e a padronização de medicamentos indicados para atendimento de doenças no âmbito do SUS. A RENAME será acompanhada do Formulário Terapêutico Nacional (FTN), que subsidiará a prescrição, a dispensação e o uso dos seus medicamentos (art. 25). A FTN contém informações científicas, isentas de conflitos de interesse e com base em evidências, sobre os fármacos cons-

19 Protocolo clínico é o documento que estabelece critérios para o diagnóstico da doença, o tratamento adequado, os medicamentos apropriados, as posologias recomendadas, os mecanismos de controle clínico e o acompanhamento e a verificação dos resultados terapêuticos, a serem seguidos pelos gestores do SUS (art. 19-N, da Lei n. 8.080/1990). 
tantes da RENAME. O Ministério da Saúde é o órgão competente para dispor sobre a RENAME e os protocolos clínicos e diretrizes terapêuticas em âmbito nacional. A cada dois anos, ele consolidará e publicará as atualizações da RENAME, do respectivo FTN e dos protocolos clínicos e diretrizes terapêuticas (art. 26).

Os Estados, o Distrito Federal e os Municípios poderão adotar relações específicas e complementares de medicamentos, em consonância com a RENAME, respeitadas as responsabilidades dos entes pelo financiamento de medicamentos (art. 27). Ainda segundo Decreto n. 7.508/2011, o acesso universal e igualitário à assistência farmacêutica pressupõe, cumulativamente: (1) estar o usuário assistido por ações e serviços de saúde do SUS; (2) ter o medicamento sido prescrito por profissional de saúde, no exercício regular de suas funções no SUS; (3) estar a prescrição em conformidade com a RENAME e os protocolos clínicos e diretrizes terapêuticas ou com a relação específica complementar estadual, distrital ou municipal de medicamentos; e (4) ter a dispensação ocorrido em unidades indicadas pela direção do SUS.

Os entes federativos poderão ampliar o acesso do usuário à assistência farmacêutica e o Ministério da Saúde poderá estabelecer regras diferenciadas de acesso a medicamentos de caráter especializado (art. 28). A RENAME e as relações complementares estaduais e municipais de medicamentos somente poderão conter produtos com registro na Agência Nacional de Vigilância Sanitária (ANVISA) (art. 29).

O propósito da Política Nacional de Medicamentos (PNM), aprovada pela Portaria GM n. 3.916/1998, do Ministério da Saúde, é garantir segurança, eficácia e qualidade dos medicamentos oferecidos no SUS, a promoção do uso racional e o acesso da população àqueles considerados essenciais. Suas principais diretrizes são o estabelecimento da relação de medicamentos essenciais, a reorientação da assistência farmacêutica, o estímulo à produção de medicamentos e a sua regulamentação sanitária.

A PNM considera que medicamentos essenciais são os produtos considerados básicos e indispensáveis para atender a maioria dos problemas de saúde da população. É um importante mecanismo para a redução dos custos dos produtos. A definição de medicamentos a serem adquiridos e distribuídos de forma centralizada deverá considerar três pressupostos básicos: (1) doenças que configuram problemas de saúde pública, ou seja, que põem em risco as coletividades; (2) doenças consideradas de caráter individual que, a despeito de atingir número reduzido de pessoas, requerem tratamento longo ou até permanente, com o uso de medicamentos de custos elevados; e (3) doenças cujo tratamento envolve o uso de medicamentos não disponíveis no mercado. A escolha de incorporação deverá, ainda, observar critérios mais específicos, relativos a aspectos técnicos e administrativos, como: (1) disponibilidade de recursos financeiros; (2) o custo-benefício e o custo-efetividade da aquisição e distribuição dos produtos em relação ao conjunto das demandas e necessidades de saúde da população; (3) a repercussão do fornecimento; (4) a necessidade de garantir dosagens adequadas.

Há outras normas mais específicas. O desenho básico da legislação relativa ao fornecimento de medicamentos, porém, é esse. O desenho revela a complexidade das políticas públicas de promoção à saúde e algumas noções essenciais ao tema: acesso universal e igualitário, uso racional dos recursos, medicina baseada em evidências, eficácia do tratamento. Esses conceitos foram, em alguma medida, incorporados pela jurisprudência, que passou a utilizá-los como critérios ou parâmetros nas decisões.

\section{FoRNECIMENTO DE MEDICAMENTOS E PRINCIPAIS MARCOS JURISPRUDENCIAIS}

O Supremo Tribunal Federal convocou, em 2009, audiência pública sobre saúde. O AgR na STA n. 175 esboçou, com base nas informações obtidas, parâmetros para solução judicial dos casos concretos que envolvem esse direito. Constatou-se a necessidade de redimensionar a questão da judicialização do direito à saúde no Brasil. Segundo o Supremo Tribunal Federal, a primeira investigação que o julgador deve fazer é sobre a existência de política pública abrangendo a prestação de saúde pretendida pela parte. Há direito sub- 
jetivo à prestação se existir a política pública. Caso a prestação não figure nas políticas do Sistema Único de Saúde, o julgador deverá observar se há: (1) omissão legislativa ou administrativa, (2) decisão administrativa de não fornecê-la ou (3) vedação legal.

A segunda investigação é a respeito do motivo para o não fornecimento de determinada ação de saúde pelo SUS. Se o Sistema Único de Saúde decidiu não custear determinado tratamento, por entender inexistirem evidências científicas suficientes para autorizar sua inclusão, houve exercício de sua legítima atribuição. Nesse caso, duas situações podem ocorrer: (1) o SUS fornece tratamento alternativo, mas não adequado a determinado paciente ou (2) tem tratamento específico para determinada patologia.

Como o Sistema Único de Saúde filiou-se à corrente da medicina baseada em evidências, o medicamento fora dos protocolos clínicos e diretrizes terapêuticas deve ser visto com reservas, por contrariar um consenso científico. O tratamento fornecido pelo SUS deverá ser privilegiado em detrimento de opção diversa, sempre que não for comprovada a ineficácia ou a impropriedade da política de saúde existente. A inexistência de tratamento na rede pública, contudo, requer solução diferente. Nesses casos, é preciso diferenciar os tratamentos puramente experimentais dos novos tratamentos ainda não testados pelo Sistema Único de Saúde. A omissão administrativa do tratamento de determinada patologia poderá ser objeto de impugnação judicial, desde que haja a produção de provas, ou seja, será imprescindível a instrução processual. ${ }^{20}$

O Supremo Tribunal Federal reconheceu a repercussão geral das controvérsias sobre a obrigatoriedade de o Poder Público fornecer medicamento de alto custo e medicamento não registrado na Agência Nacional de Vigilância Sanitária. ${ }^{21}$

Embora o julgamento não tenha sido concluído, o portal de notícias do Supremo Tribunal Federal informa que três ministros já votaram e apresentaram parâmetros para nortear as decisões judiciais a respeito dos temas. A tese do Ministro Marco Aurélio foi:

O reconhecimento do direito individual ao fornecimento, pelo Estado, de medicamento de alto custo, não incluído em Política Nacional de Medicamentos ou em Programa de Medicamentos de Dispensação em Caráter Excepcional, constante de rol dos aprovados, depende da demonstração da imprescindibilidade - adequação e necessidade -, da impossibilidade de substituição do fármaco e da incapacidade financeira do enfermo e da falta de espontaneidade dos membros da família solidária em custeá-lo, respeitadas as disposições sobre alimentos dos artigos 1.694 a 1.710 do Código Civil, e assegurado o direito de regresso.

O Ministro Luís Roberto Barroso apresentou, com relação aos medicamentos de alto custo, a seguinte tese: "O Estado não pode ser obrigado por decisão judicial a fornecer medicamento não incorporado pelo SUS, independentemente de custo, salvo hipóteses excepcionais, em que preenchidos cinco requisitos". Os cinco requisitos seriam: "incapacidade financeira de arcar com o custo correspondente; demonstração de que a não incorporação do medicamento não resultou de decisão expressa dos órgãos competentes; inexistência de substituto terapêutico incorporado pelo SUS; comprovação de eficácia do medicamento pleiteado à luz da medicina baseada em evidências; propositura da demanda necessária em face da União, já que a responsabilidade pela decisão final sobre a incorporação ou não de medicamentos é exclusiva desse ente federativo". Em relação ao problema dos medicamentos não autorizados pela Anvisa, a tese apresentada foi:

O Estado não pode ser obrigado a fornecer medicamentos experimentais, sem eficácia e segurança comprovadas, em nenhuma hipótese. Já em relação a medicamentos não registrados na Anvisa, mas com comprovação de eficácia e segurança, o Estado somente pode ser obrigado a fornecê-los na hipótese de irrazoável mora da agência em apreciar o pedido de registro (prazo superior a 365 dias),

20 BRASIL. Supremo Tribunal Federal. Agravo regimental. STA 175 AgR. Tribunal Pleno. Relator(a): Min. GILMAR MENDES (Presidente. Julgado em 17/03/2010, DJe-076 DIVULG 29-04-2010 PUBLIC 30-04-2010 EMENT VOL-02399-01 p. 70.

21 RE 566471 RG, Relator(a): Min. MARCO AURÉLIO, julgado em 15/11/2007, DJe-157 DIVULG 06-12-2007 PUBLIC 07-12-2007 DJ 07-12-2007 PP-00016 EMENT VOL-02302-08 PP-01685 / RE 657718 RG, Relator(a): Min. MARCO AURÉLIO, julgado em 17/11/2011, ACÓRDÃO ELETRÔNICO DJe-051 DIVULG 09-03-2012 PUBLIC 12-03-2012 REPUBLICAÇÃO: DJe-092 DIVULG 10-05-2012 PUBLIC 11-05-2012. 
quando preenchidos três requisitos: 1) a existência de pedido de registro do medicamento no Brasil; 2) a existência de registro do medicamento em renomadas agências de regulação no exterior; e 3) a inexistência de substituto terapêutico com registro no Brasil. As ações que demandem fornecimento de medicamentos sem registro na Anvisa deverão necessariamente ser propostas em face da União.

O Ministro Edson Fachin também propôs cinco parâmetros para auxiliar o julgador:

1) necessária a demonstração de prévio requerimento administrativo junto à rede pública; 2) preferencial prescrição por médico ligado à rede pública; 3) preferencial designação do medicamento pela Denominação Comum Brasileira (DCB) e, em não havendo a DCB, a DCI (Denominação Comum Internacional); 4) justificativa da inadequação ou da inexistência de medicamento/ tratamento dispensado na rede pública; 5) e, em caso de negativa de dispensa na rede pública, é necessária a realização de laudo médico indicando a necessidade do tratamento, seus efeitos, estudos da medicina baseada em evidências e vantagens para o paciente, além de comparar com eventuais fármacos fornecidos pelo SUS.

Outras premissas foram, ainda, apresentadas por ele:

1) controle de legalidade (não deve haver erro manifesto na aplicação da lei, nem pode existir abuso de poder); 2) controle da motivação (aferir se as razões do ato regulatório foram claramente indicadas, estão corretas e conduzem à conclusão a que chegou a administração pública); 3) controle da instrução probatória da política pública regulatória (exigir que a produção de provas, no âmbito regulatório, seja exaustiva, a ponto de enfrentar uma situação complexa); e 4) controle da resposta em tempo razoável (que impõe à agência o dever de decidir sobre a demanda regulatória que lhe é apresentada, no prazo mais expedito possível). ${ }^{22}$

Outro julgamento de destaque, pelo Supremo Tribunal Federal, sobre o direito à saúde ocorreu no deferimento da medida liminar requerida na ADI n. 5.501, quando se suspendeu a eficácia da Lei n. 13.269/2016, que autorizava o uso da fosfoetanolamina sintética para tratamento do câncer. O Supremo Tribunal Federal considerou que o fornecimento de substância sem o registro no órgão competente viola a preservação da saúde dos cidadãos em geral. ${ }^{23}$ Embora tenha sido em caráter provisório, o julgamento se destaca por ter abordado temas como a função regulatória da Anvisa para registrar medicamentos, vigilância sanitária, reserva da administração para definição de políticas públicas, análises farmacotécnica e de eficácia e segurança.

A evolução jurisprudencial e a necessidade de fixar parâmetros para aperfeiçoar as intervenções judiciais no âmbito do direito à saúde foi reconhecida pelo Superior Tribunal de Justiça. Recentemente, aquele tribunal fixou a tese de que a obrigatoriedade do poder público de fornecer medicamentos não incorporados em atos normativos do SUS exige a presença cumulativa três requisitos: (1) comprovação, por meio de laudo médico fundamentado e circunstanciado expedido por médico que assiste o paciente, da imprescindibilidade ou necessidade do medicamento, assim como da ineficácia, para o tratamento da moléstia, dos fármacos fornecidos pelo SUS; (2) incapacidade financeira de arcar com o custo do medicamento prescrito; (3) existência de registro na ANVISA. ${ }^{24}$ É citado neste artigo apenas para demonstrar que os parâmetros que vinham se cristalizando na jurisprudência foram acolhidos pelo Superior Tribunal de Justiça.

O Conselho Nacional de Justiça (CNJ) tem trabalhado no âmbito administrativo para aperfeiçoar as decisões judiciais que afetam as políticas públicas de saúde. Destacam-se, a respeito, a Recomendação n. $31 / 2010$, que traça diretrizes aos magistrados quanto às demandas judiciais envolvendo a assistência à saúde; o Fórum Nacional do Judiciário para monitoramento e resolução das demandas de assistência à Saúde (Fórum da Saúde); e o e-NatJus, um cadastro nacional de pareceres, notas e informações técnicas, cuja finalidade é oferecer base científica para as decisões dos magistrados.

22 BRASIL. Supremo Tribunal Federal. Pedido de vista adia julgamento sobre acesso a medicamentos de alto custo por via judicial. Disponível em: <http://www.stf.jus.br/portal/cms/verNoticiaDetalhe.asp?idConteudo=326275\&tip=UN>. Acesso em: 6 maio 2018.

23 BRASIL. Supremo Tribunal Federal. Ação Direta de Inconstitucionalidade. ADI 5501 MC. Tribunal Pleno. Relator(a): Min. MARCO AURÉLIO. Julgado em 19/05/2016, PROCESSO ELETRÔNICO DJe-168 DIVULG 31-07-2017 PUBLIC 01-08-2017. 24 BRASIL. Superior Tribunal de Justiça. Recurso especial. REsp 1657156/RJ. Primeira Seção. Rel. Ministro Benedito Gonçalves. Julgado em 25/04/2018, DJe 04/05/2018. 
Conforme se observa por toda a exposição das complexidades envolvidas na definição do dever jurídico do Estado em prestar o direito à saúde, há dificuldade em se identificar a existência de direito líquido e certo nos casos em que se discute concessão de medicamentos fora do rol daqueles previstos nas normas e protocolos do SUS, formulados e limitados por todos meio de todos os procedimentos aos quais já se fez referência ao longo do presente trabalho. No caso exemplar acima exposto, o impetrante sofre de hemofilia B grave e pretende ser tratado com o concentrado de fator IX recombinante. No caso em estudo, não ficou provado que o tratamento oferecido pela rede pública seja ineficaz para o tratamento do impetrante. Dessa maneira, em virtude da controvérsia científica que foi estabelecida, não existe direito líquido e certo à concessão da medicação.

Há uma importante discussão científica sobre a opção pelo mediamente pleiteado que não pode ser resolvida pelo recurso retórico à evidência do direito à saúde como expresso na Constituição Federal. Poder-se ia dizer que o principal fundamento para a prescrição do concentrado recombinante é somente a redução dos riscos de uma eventual contaminação. Em sentido contrário ao argumento de que o medicamento pleiteado traria melhora ao tratamento do impetrante, o relatório médico no qual se prescreve o medicamento postulado não demonstra que a medicação disponibilizada pelo Ministério da Saúde tem sido ineficaz para o impetrante. Segundo a médica subscritora, a tecnologia recombinante é superior à baseada em plasma humano, especialmente quanto aos riscos de contaminação. A leitura atenta do relatório médico, contudo, revela que em momento algum é mencionado que o tratamento da rede pública não tem funcionado para o caso específico do impetrante. Trata-se de uma preferência em abstrato da profissional. Isso por si só já revela que a impossibilidade da escolha do mandado de segurança para a discussão sobre os limites e a extensão do direito à saúde como expressão de uma política pública.

A profilaxia primária para hemofilia grave, no Brasil, deve seguir o protocolo estabelecido pela Portaria n. 364/2014, do Ministério da Saúde. O protocolo contém orientações relacionadas ao tratamento profilático de crianças acometidas por Hemofilia A e B grave, para prevenir o desenvolvimento da artropatia hemofílica, reduzir outros sangramentos e melhorar a qualidade de vida dos pacientes. Os critérios são de caráter nacional e devem ser utilizados pelas Secretarias de Saúde dos Estados, do Distrito Federal e dos Municípios.

O termo de consentimento presente no protocolo explica que a profilaxia primária em hemofilia é o nome que se dá ao tratamento para pacientes com hemofilia A ou B grave de forma profilática, isto é, independentemente de o paciente apresentar sangramento e por tempo prolongado e ininterrupto. De acordo com o documento, a profilaxia primária é recomendada e reconhecida pela Organização Mundial da Saúde e Federação Mundial de Hemofilia como o tratamento de eleição para a forma grave da hemofilia A e B. O tratamento consiste na infusão de concentrado de fator VIII (para hemofilia A grave) ou fator IX (para hemofilia B grave) antes da ocorrência do sangramento. O paciente recebe a infusão do concentrado do fator 1 a 2 vezes por semana, para hemofilia B, e 1 a 3 vezes por semana, para hemofilia A, com doses escalonadas. A profilaxia primária impede que o paciente com hemofilia grave desenvolva as complicações da doença secundárias aos sangramentos de repetição, principalmente da artropatia hemofílica, que pode levar a deformidades e sequelas motoras irreversíveis.

A Federação Mundial de Hemofilia não expressa preferência por recombinantes sobre os concentrados derivados de plasma. A escolha deve ser feita de acordo com critérios locais, de cada país. ${ }^{25}$

O impetrante foi avaliado por junta médica oficial, por força da decisão proferida pelo Presidente do Supremo Tribunal Federal na suspensão de segurança. A junta médica oficial concluiu que era necessário, apenas, aumentar a dosagem e a frequência do tratamento, mas o produto poderia permanecer o mesmo. A decisão do Supremo Tribunal Federal não concedeu o tratamento pretendido pelo impetrante. A leitura atenta da fundamentação revelou o oposto: a medida liminar, deferida no Tribunal de Justiça do Distrito Fe-

25 FEDERAÇÃO MUNDIAL DE HEMOFILIA. Manual para tratamento da hemofilia. Disponível em: <http://www1.wfh.org/ publications/files/pdf-1472.pdf>. Acesso em: 02 maio 2018. 
deral e dos Territórios, foi suspensa. O Ministro Ricardo Lewandowski observou que as evidências trazidas até aquele momento indicavam a regularidade do protocolo seguido pelo Ministério da Saúde. Deixou, porém, em aberto a possibilidade de que fosse dispensado outro tratamento, desde que determinado por junta médica oficial. A junta médica não considerou necessário o uso do concentrado de fator IX recombinante. Concluiu, apenas, que a dosagem e a frequência precisavam ser alteradas.

Expressando uma dimensão de complexidade da questão, um dos medicamentos sugeridos pela médica do impetrante, com base no fator IX recombinante, foi o Benefix®. Em 2016, o Laboratório Farmacêutico Pfizer LTDA solicitou à CONITEC a avaliação do medicamento alfanonacogue-Benefix ${ }^{\circledR}$, fator IX recombinante, para o tratamento de pacientes com hemofilia B menores de 19 anos. A justificativa seria diminuir o risco de possíveis contaminações virais não identificadas, que poderiam ocorrer nos fatores derivados de plasma que o SUS já disponibiliza. A CONITEC avaliou o medicamento, na Consulta Pública n. 39, e decidiu não o incorporar ao SUS. No exame dos estudos científicos, o órgão entendeu não haver diferença entre a tecnologia proposta e a já disponível no SUS, em relação à ocorrência de efeitos indesejáveis. O órgão não chegou à conclusão quanto à eficácia da tecnologia, quando confrontada com a disponível no SUS, porque não foi apresentado estudo comparativo. A CONITEC observou, também, que o preço proposto para o alfanonacogue é cerca de quatro vezes maior que o fator IX plasmático, já disponível no SUS. ${ }^{26}$ A avaliação levou em consideração as evidências científicas e os impactos orçamentários da adoção da tecnologia, optando por não a incorporar.

Duas últimas menções a julgados exemplificam a complexidade da questão. O Ministro Teori Albino Zavascki, quando atuava no Superior Tribunal de Justiça, mencionou no MS 8.895/DF que, embora seja angustiante para o julgador, não é possível resolver, por meio de liminares, os problemas de saúde, de alimentação, de habitação e de educação. Os direitos a prestações materiais estão sujeitos às possibilidades do Estado. Os juízes não têm o conhecimento técnico e científico necessário para discordar quando a autoridade diz que o tratamento pretendido não é recomendável cientificamente e a tarefa de fazer as opções políticas relativas à saúde cabe aos profissionais de saúde:

Estamos diante de um caso típico de direito fundamental social, os chamados direitos à prestação, que não são infinitos ou absolutos. Em qualquer país do mundo estão sujeitos às possibilidades do Estado. São, portanto, direitos "sob reserva de possibilidade social", como os conceitua a doutrina (José Carlos Vieira de Andrade, "Os Direitos Fundamentais na Constituição Portuguesa de 1976”, 2ª ed., Almedina, p. 59).

Oxalá pudéssemos, em nome da Constituição, concedendo liminares, resolver os graves problemas brasileiros de saúde, de alimentação, de habitação, de educação. Claro que é muito angustiante a situação descrita nos autos. Quem não se angustia e se sensibiliza numa situação dessas? Entretanto, que elementos temos no mandado de segurança para duvidar do ato da autoridade que diz que o tratamento pretendido não é recomendável cientificamente? Que autoridade, nós, juízes, temos para duvidar disso? Não vejo como não considerar legítima a opção do administrador, ainda mais fundada no parecer. Ponhamo-nos no papel de quem tem o dever técnico de administrar a escassez de recursos num País pobre como o nosso, e de fazer as opções políticas para lhes dar melhor destinação. Portanto, não há como ter presente, no caso, direito líquido e certo a obter do Estado a liberação da vultosa quantia necessária ao atendimento individual da impetrante.

Não há dúvida de que a saúde é um direito fundamental, mas, também é certo, não se trata de direito absoluto. Ele será atendido na medida das possibilidades, inclusive, financeiras, da sociedade. No caso, ademais, há uma recomendação técnica contrária, que o Judiciário não tem autoridade científica para contestar. $^{27}$

26 COMISSÃO NACIONAL DE INCORPORAÇÃO DE TECNOLOGIAS NO SUS - CONITEC. Ministério da Saúde. Relatório de recomendação: Alfanonacogue - Benefix ${ }^{\circledR}$ para hemofilia B em pacientes menores de 19 anos de idade. Disponível em: <http://conitec.gov.br/images/Consultas/Relatorios/2016/Relatorio_Fator_IX_recomb_CP_39_2016.pdf>. Acesso em: 2 maio 2018.

27 COMISSÃO NACIONAL DE INCORPORAÇÃO DE TECNOLOGIAS NO SUS - CONITEC. Ministério da Saúde. Relatório de recomendação: Alfanonacogue - Benefix ${ }^{\circledR}$ para hemofilia B em pacientes menores de 19 anos de idade. Disponível em: 
No segundo caso, o Desembargador Diaulas Ribeiro, do Tribunal de Justiça do Distrito Federal e Territórios, apontou, no voto proferido no MSG 2016.00.2.022665-4, julgado pela Segunda Câmara Cível, em 12 de dezembro 2016, o impacto orçamentário caso o Distrito Federal seja obrigado a fornecer o fator IX recombinante de longa duração. O tratamento de 50 (cinquenta) pacientes com hemofilia $\mathrm{B}$, usando o fator IX hemoderivado, custaria aos cofres públicos o valor de R $\$ 6.106 .000 .00$ (seis milhões cento e seis mil reais) por ano. O tratamento com o fator IX recombinante custaria $\mathrm{R} \$ 43.556 .000,00$ (quarenta e três milhões quinhentos e cinquenta e seis mil reais). O gasto será de R \$198.800.000,00 (cento e noventa e oito milhões e oitocentos mil reais), se for utilizado o fator IX recombinante de longa duração. O orçamento de 2016 da Secretaria de Saúde, para aquisição de todos os medicamentos para tratar todos os pacientes assistidos no Distrito Federal, foi de $\mathrm{R} \$ 166.502 .397,53$ (cento e sessenta e seis milhões quinhentos e dois mil trezentos e noventa e sete reais e cinquenta e três centavos). O tratamento com o fator IX recombinante de longa duração de apenas cinquenta pacientes custará, portanto, 32 (trinta e dois) milhões de reais a mais do que todo o orçamento destinado para adquirir medicamentos para a integralidade dos pacientes do Distrito Federal.

Como foi evidenciado, a definição do dever jurídico do Estado quanto à prestação do direito à saúde na forma da concessão de medicamentos e procedimentos médicos não estabelecidos em normas próprias do sistema é extremamente problemática, debatível e incerta. As complexidades da execução da política pública de concessão de medicamentos e procedimentos médicos revelam que, nesses casos, atalhos processuais, como é o caso da utilização dos mandados de segurança para a dedução desse tipo de pretensão, não são recomendáveis.

\section{RONALD DWORKIN E A REFLEXÃo LIBERAL SOBRE IGUALDADE E REGRA}

A intervenção judicial em políticas públicas pode ser problemática, dada a sua complexidade, as conseqüências possíveis, as variadas dificuldades da questão, além da aparente necessidade de uma consideração sobre os limites e a extensão dos direitos prestacionais enunciados na Constituição Federal, no caso em análise, o direito à saúde. O direito à saúde, como disposto no art. 196 a 200, mas sobretudo nos 196 e 197, da CF, carece, como já mencionado, de uma leitura jurídico-política, neste aspecto incluído o conceito de política pública. Trata-se de colocar à disposição dos sujeitos, de forma distributiva, um complexo de ações, produtos, serviços e instalações de forma isonômica, de forma a respeitar o princípio basilar do direito ao tratamento igual de iguais e desigual de desiguais, na medida de suas desigualdades, o conhecido suum cuique tribuere. Esse problema conduz a uma reflexão sobre a dificuldade de lidar com a igualdade perante a lei quando o texto legal apresenta uma grande abertura semântica. ${ }^{28}$

O estabelecimento do que significam os direitos fundamentais sociais, sobre os quais devem incidir políticas públicas que viabilizem sua fruição, como é o caso da educação, da saúde e da previdência, por exemplo, passa necessariamente, por uma reflexão sobre qual o tipo de sociedade na qual vivemos e sobre seu projeto futuro. Julgar essas questões sem uma concepção prévia consciente sobre que abordagem metodológica se deve utilizar para alocar esses direitos na prática, já que suas condições de fruição são submetidas a limites materiais de efetivação, é, para dizer o mínimo, precário. Essa forma de abordagem teria como resultado uma decisão deficitariamente fundamentada.

Um recorte teórico possível para o tratamento dessas questões seria aquele já explorado por alguns au-

<http://conitec.gov.br/images/Consultas/Relatorios/2016/Relatorio_Fator_IX_recomb_CP_39_2016.pdf>. Acesso em: 2 maio 2018.

28 A igualdade supõe a diversidade, ou a desigualdade. Como problema de organização social, a desigualdade depende de como se compreende os aspectos de igualdade que devem estar em relevo como funcionamentos básicos que devem ser propiciados a todos e cada um. Nesse sentido, a diversidade humana é uma condição de possibilidade para se compreender e refletir sobre o problema da igualdade. SEN, Amartya. Desigualdade reexaminada. Rio de Janeiro: Record, 2001. p. 29. 
tores, segundo o qual a herança da discussão liberal sobre a justiça de um arranjo político institucional teria derivado nas seguintes correntes de pensamento: liberalismo, comunitarismo e republicanismo, além do feminismo e do marxismo analítico. ${ }^{29}$

A discussão sobre o direito à saúde pode ser realizada nessas distintas perspectivas, mas talvez interesse, por ser intuitivamente mais próxima do que se tem como padrão decisório hoje nos tribunais brasileiros, a perspectiva liberal, na forma moderada de Ronald Dworkin. O autor norteamericano trata em alguns textos de sua extensa produção literária do problema do direito à saúde. Propõe-se que se circunscrevam, de seu pensamento, três aspectos sobre o problema da alocação dos recursos relacionados à fruição do direito à saúde: 1. os direitos individuais são trunfos em face das políticas públicas; 2. os princípios de organização da reflexão sobre o direito à saúde: resgate e seguro prudente; 3. o sentido da afirmação liberal de que o indivíduo precede ao todo quando se trata de direitos morais coletivos.

Ronald Dworkin propõe uma abordagem metodológica liberal sobre os limites e a extensão do direito à saúde, supondo o espelhamento da racionalidade alocativa individual ao plano coletivo. ${ }^{30}$ Estabelece como premissa que uma comunidade política se afirma como legítima quando tem uma consideração igualitária sobre os direitos dos cidadãos.

O argumento de Ronald Dworkin sobre a Teoria da Moralidade política deve se localizar em uma teoria mais geral dos valores humanitários da ética e da moralidade, do status e da integridade do valor, e do caráter e da possibilidade da verdade objetiva. Nesse sentido, há um compromisso fundamental com relação ao valor de uma vida humana e com relação à responsabilidade de cada indivíduo de descobrir esse valor em sua própria vida. Esse individualismo ético tem como base duas premissas: a. igual importância e b. responsabilidade especial.

A Teoria da Igualdade de Ronald Dworkin deve disciplinar um cenário que é marcado por ao menos três dimensões: jurídico-política, econômica e moral. Nesse contexto, as políticas públicas são o repositório que tenta corrigir as distorções ou aviltamentos próprios ao desequilíbrio entre oferta e procura, e o problema que se coloca é como articular um conceito de igualdade que contemple a diversidade cultural, problema que se refere, também, e talvez especialmente, no direito brasileiro, à abertura para percepções de atribuições de sentido de normas garantidoras de direitos.

As normas precisam fazer sentido, coletivamente. Requerer igualdade quando são oferecidas as mesmas oportunidades e horizontes é bem diferente de se exigir o seguimento de normas que não fazem sentido exatamente por desconhecerem sua materialidade cultural, econômica ou jurídica. Submeter-se à noção de aplicação coletiva da norma pode não fazer sentido se seu descumprimento faz parte do padrão comportamental da elite ou se decisões são percebidas como instáveis e incoerentes, tendo em vista algum sentido prima facie de um determinado texto normativo. ${ }^{31}$

Colocado no âmbito dos Estados Unidos da América, o tema da justiça e do alto custo da saúde é apresentado na forma das seguintes perguntas: quanto deve uma nação gastar com a saúde das pessoas? Como saber se as demais nações não estão gastando muito pouco ou demais em relação à primeira? Quanta assistência médica uma sociedade razoável deve tornar acessível a todos? Podemos oferecer a todos a assistência médica que os mais ricos dentre nós podem comprar para si? Como decidir qual é o nível mínimo de assistência médica que a justiça exige que até os mais pobres tenham? Se a nação não pode pagar todos

29 GARGARELLA, Roberto. As teorias da justiça depois de Rawls: um breve manual de filosofia política. São Paulo: WMF Martins Fontes, 2008. passim.

30 Para Amartya Sen, as decisões sobre alocação equânime de recursos enseja sempre a consideração sobre quem, porque e como indivíduos (ou grupos) terá direito a algo. São decisões trágicas, posto que há um sacrifício a ser imposto a alguém em qualquer das situações resultantes de qualquer decisão. Assim como em Dworkin, a igualdade se expressa na ideia de igual consideração. Como a igualdade é um conceito controverso e debatível, surge a pergunta que ancora a materialização desse princípio: igualdade de quê? 31 FREITAS FILHO, Roberto; SILVA, Frederico Augusto Barbosa da. O judiciário cordial, a violência e a corrupscão na América Latina. Disponível em: <https://portalrevistas.ucb.br/index.php/REPATS/article/view/8210>. Acesso em: 2 jul. 2018. 
os exames e tratamentos que seus cidadãos venham a querer ou precisar, como deve decidir, como nação, quanto gastar coletivamente e com cada cidadão? O que é um tratamento médico apropriado depende do que seria injusto restringir com fundamento no alto custo.

Para responder a essas questões, Ronald Dworkin coloca hipoteticamente dois princípios aparentemente confrontantes, o do resgate e o do seguro prudente. Como premissas o Princípio do Resgate dispõe, em resumo, que: a. vida e saúde são os bens mais importantes e; b. todos devem receber tratamento, sem que seja feita qualquer consideração de natureza econômica. Entretanto, o autor adverte que o Princípio do Resgate é inútil para o fim de responder às perguntas sobre o racionamento. Esse princípio diz que temos de gastar tudo que pudermos na saúde, sem limites. ${ }^{32}$

Quais seriam, então, os critérios para determinar quem precisa o que, em termos de decisão sobre a política pública sobre alocação de recursos escassos? Uma primeira observação é que qualquer decisão de política pública sobre a saúde deve considerar os incentivos econômicos. Se não considerados os aspectos econômicos, os gastos com saúde são irracionais, desse ponto de vista, pois o sistema (judiciário, no caso) faz para as pessoas as escolhas que elas não fariam sozinhas, e o resultado é que há um exagero no cálculo dos gastos coletivos.

Os economistas conservadores defendem a submissão da saúde à lógica do mercado. Cada um por si. Ronald Dworkin diz que esse modelo de organização é igualmente inaceitável por três motivos: 1. A distribuição de riqueza é injusta. 2. As pessoas têm informação insuficiente. 3. Em mercado desregulado (ou fracamente regulado), as operadoras cobram preços caros para pessoas que têm doenças graves, preços proibitivos. Frente a essas dificuldades, a resposta de Ronald Dworkin é o chamado seguro prudente ideal, uma proposta metodológica de tratamento da questão consistente na distribuição de riqueza e renda justa, tanto quanto possível; a informação deve ser partilhada por todos, resultando em simetria perfeita de informações; finalmente, que houvesse um véu de ignorância sobre as doenças, sua incidência e seus riscos, deveria ser suportado por todos os envolvidos. ${ }^{33}$

A prudência faz com que pessoas façam cálculos de probabilidade sobre o custo de medicamentos e tratamentos e façam seguro com base nesses prognósticos de possibilidades. Assim, jovens têm planos de saúde mais básicos do que idosos, por exemplo. É possível, portanto, usar a hipótese liberal do incentivo individual para fazer uma reflexão para produzir um modelo de política que atenderá a limites e possibilidades de fruição do direito à saúde de maneira coletiva e distributiva. O problema da igualdade, nesse caso, retorna ao ponto da consideração coletiva do impacto das decisões de saúde para a comunidade política como um todo, o que impede que seja atribuído ao juízo sobre o tema uma noção de direito público subjetivo na perspectiva radicalmente individualista, como se tem feito na jurisprudência brasileira.

Tratando-se dos limites materiais e da natureza do direito à saúde, uma pretensão individual descolada da consideração econômica que dá sentido ao direito à saúde na sua acepção distributiva não pode prevalecer, a despeito das potenciais consequências individuais da afirmação de tais limites. Não há trunfo individual em relação às políticas públicas de saúde nas hipóteses em que não há intervenção judicial na formulação destas, com a introdução de regras, seja por inexistência, seja por ampliação de hipóteses normativas. Em relação aos direitos morais coletivos, a leitura jurídico política da Constituição Federal supõe a hipótese de extrapolação do modelo de escolhas individuais para as coletivas, o que, novamente, impede a aplicação de uma episteme calcada na ideia individualista radical da existência de um direito público subjetivo do sujeito em face da comunidade política, sem maiores considerações consequencialistas.

32 DWORKIN, Ronald. A virtude soberana: a teoria e a prática da igualdade. São Paulo: Martins Fontes, 2005. p. 434-435.

33 DWORKIN, Ronald. A virtude soberana: a teoria e a prática da igualdade. São Paulo: Martins Fontes, 2005. p. 441. 


\section{Considerações finais}

Apresentada a extrema dificuldade da questão evidenciada no caso exemplar referido, na presente seção pretende-se apresentar um cenário da complexidade envolvida na identificação de um dever jurídico com base em textos normativos que são, em essência, avaliatórios, e que devem ser preenchidos de significado no contexto da sociedade brasileira contemporânea, que partilha, com outras ocidentais de mesmas características, características que dificultam a obtenção de consensos semânticos normativos. Argumenta-se que não é suficiente o recurso a expressões como dignidade da pessoa bumana e mínimo existencial, por exemplo, para fundamentar, adequadamente, uma decisão em que se discuta o dever jurídico do Estado em garantir direito à saúde aos sujeitos de direito. A postulação pretende, além disso, amparar a hipótese de que intervir em políticas públicas prestacionais, como a relativa ao direito à saúde, especialmente por meio do uso de instrumentos processuais de cognição estreita, caso do mandado de segurança, leva a resultados que promovem, coletivamente, mais dificuldades do que soluções. Em síntese, pretende-se refletir sobre a dificuldade de definir os limites dos deveres jurídicos decorrentes dos artigos constitucionais que tratam do direito à saúde.

Um dos problemas mais instigantes e dramáticos do raciocínio jurídico e da prática do saber prudencial do direito é o da nomeação dos objetos. Um fato da vida passa a ser um fato jurídico porque é nomeado como tal. Falar sobre o direito e fazê-lo, na prática, é um complicado exercício de identificações e distinções de coisas, fatos e relações. Quando se afirma que alguém é negro, hipossuficiente, ou que um produto é supérfluo ou essencial, ou mesmo que há uma relação de consumo em uma determinada compra, em cada um desses processos aparentemente triviais há uma imensa carga de complexidade, já que se definem coisas com base em uma noção de identidade. Ao compor uma determinada categoria, seja uma classe, um gênero ou uma espécie, dentre outros, o objeto recebe um determinado tipo de tratamento jurídico. Em outras palavras, se submete a um tipo de regime jurídico, sendo regulado no âmbito de um determinado sistema normativo (ou subsistema), no qual há sentidos conceituais e interpretativos específicos aplicáveis aos problemas e situações jurídicas enfrentados. Por exemplo, se há uma relação de consumo, o contratante em um contrato de compra e venda será, por pressuposição legal, vulnerável. Em relação a ele, serão aplicadas regras de interpretação das normas que compõe o subsistema de maneira a protegê-lo, inclinando o julgador a, ainda a guisa de exemplo, interpretar o sentido das cláusulas contratuais de modo que lhe seja mais favorável.

O processo mental de qualificar um fato da vida como um fato jurídico equivale a estabelecer uma identidade, a qual, na medida em que sejam estabilizados o sentido e o significado daquilo sobre o que se fala, por meio do uso prático da linguagem daquela determinada maneira, torna aquela palavra e seu significado um critério que me permite dizer que se fala a verdade ou não. Ou seja, o uso da linguagem, com base na estabilidade de sentido das palavras, permite construir identidades e distinções, igualdades e desigualdades, e, dessa forma, em alguma medida, estabelecer os critérios de verificação veritativa por meio dos quais se pode afirmar, por exemplo, que é errado dizer que um livro é uma garrafa de vidro ou que há um consumidor não vulnerável em uma relação de consumo.

A questão da fixação de sentido da norma tem uma dimensão especialmente importante, a da determinação do dever jurídico originário, a partir do qual se pode verificar a ocorrência de descumprimento. Como sabido, há deveres legais e contratuais, além dos deveres decorrentes da reiteração de padrões de conduta que resultam em expectativas contrafáticas normativas.

As demandas de saúde são levadas ao Poder Judiciário por meio de mandado de segurança, mas algumas características desse instrumento processual complexificam ainda mais a análise do problema. Nesse caso as questões processuais e o mérito se confundem, na medida em que há necessidade de uma providência jurisdicional muito rápida. Não há espaço para a produção de provas, realização de perícia, oitiva de testemunhas, dentre outras. Ou se tem o direito líquido e certo, com prova pré constituída, ou a via processual a ser utilizada é outra, não o mandado de segurança. 
Admite-se, para efeito argumentativo no presente artigo, que há algum núcleo de objetividade e verdade em tudo o que se afirma, segundo o qual a língua é inteligível intersubjetivamente e, com base nessa premissa, pode-se dialogar sobre posições morais, políticas e estéticas de forma racional. Nesse sentido, são excluídas as posições céticas como a dos pragmatistas e a dos desconstrucionistas acerca do problema da verdade na linguagem.

Acompanhando Bourdieu, o direito é um campo em que há posições de nomeação da verdade jurídica. O poder de nomeação da realidade que transmuta uma afirmação sobre algo possível em uma constatação de algo ocorrido, presente em várias dessas atividades, seja a do jurista (sobretudo a do julgador), a do jornalista, professor e de atores dos demais campos em que isso ocorre, dá-se em um campo de realização de objetivos social e democraticamente relevantes. No caso dos campos não jurídicos, por exemplo, a informação correta e o controle social dos poderes institucionalmente constituídos, a formação de estudantes, inclusive ideológica e, no jurídico, a jurisdição como exercício de distribuição de justiça na forma de decisões normativas como instrumento de controle social e instrumento de realização de valores sociais de coesão, como a justiça e a igualdade cidadã. ${ }^{34}$

Em uma sociedade como a brasileira, marcada por graves contradições sociais e econômicas, por uma distribuição do poder profundamente assimétrica e por um histórico de precária formação para a participação política e, consequentemente, um igualmente precário exercício dessa mesma atividade pelos sujeitos, a força da palavra que constitui a verdade normativa é vigorosa e eficaz, produzindo efeitos poderosos. Produzem-se, com certa facilidade, verdades sobre identidades e sobre igualdades e desigualdades. Naturalmente, não se desconsidera que há, sempre, uma luta competitiva pela posição que melhor propicia o poder de nomeação da realidade, da construção narrativa da verdade.

Aliado ao grande poder de nomeação que se pode exercer em uma sociedade com as características acima referidas, provavelmente se experimenta, como civilização, a radicalização do deslocamento do sentido de orientação normativa de qualquer padrão moral forte ou qualquer consenso valorativo a partir de elementos de coesão social para um modelo de normatividade em que os seus elementos constitutivos estejam fundados na radicalização do individualismo e, consequentemente, no pacta sunt servanda. Em uma sociedade em que os conceitos, as relações e os status são estabelecidos em função das preferências pessoais e em uma noção antikantiana de liberdade, o sujeito pode determinar, por exemplo, o seu direito à saúde, o que seja casamento, qual o seu gênero e como se define a sua família.

Para além das condições estruturais econômicas e sociais da sociedade brasileira, vive-se globalmente aquilo que Sigmund Bauman chamou de modernidade líquida, na qual os sentidos das relações e das experiências pessoais e coletivas são fluidos, vagos, inconstantes, vazios normativa e criticamente. ${ }^{35}$ A sociedade líquida, na qual se vivencia a modernidade líquida, tem raiz na pós-modernidade que, como diz Umberto Eco, é um termo guarda-chuva que abarca uma variedade de fenômenos literários, filosóficos, linguísticos, artísticos, nem sempre alinhados de modo coerente. ${ }^{36}$

Em síntese, a crise de orientação normativa e do conceito de comunidade levou à radicalização de um individualismo desenfreado em que tudo é fluido e incerto. Nesse cenário, o consumismo, por exemplo, é o lugar de realização de um ideal de vida frívolo e sem ideologias ou partidos, sem algo pelo que lutar ou a que combater. Até mesmo o desejo de consumo se torna, nessa realidade, compulsivamente liquefeito, fugaz.

34 Há outros campos em que se manifesta o poder de nomeação da realidade, não necessariamente jurídica, mas com resultados práticos importantes para o direito. Um exemplo é a atividade da imprensa, em que é grande a força da palavra construída na forma de um trabalho textual, de uma narrativa que se pretende coerente. Aquilo que é publicado em um jornal, em uma revista, ou qualquer outro meio de comunicação social torna-se, quase que magicamente, verdade. Não raro ouve-se: "É verdade, deu no Jornal da Globo!" (ou SBT, ou Record, dentre outros). O poder da mídia, dos jornalistas, dos veículos de comunicação e, mais recentemente, de instrumentos de informação de massa como as redes sociais, é imenso.

35 BAUMAN, Sigmund. Modernidade líquida. Rio de Janeiro: Zahar, 2001.

36 ECO, Umberto. Pape, satàn, aleppe: crônicas de uma sociedade líquida. Rio de Janeiro: Record, 2017. p.9. 
Ele é apenas um momento anterior ao da obsolescência programada ardilosamente pelo modelo de produção em que se vive. O consumo de celulares por jovens e o fenômeno do fast fashion são exemplos claros desse tipo de consumismo. No plano da circulação da informação, as redes sociais e a internet como um todo nos transformou em atores e objetos de exposição e avaliação constantes. Tuito, ergo sum!, diria Umberto Eco. ${ }^{37}$

Andrew Keen sugere que há uma hipervisibilidade que se manifesta em uma arquitetura de isolamento humano levando a uma menor sociabilidade. Isso por que

em vez de nos unir entre os pilares digitais de uma polis aristotélica, a mídia social de hoje na verdade estilhaça nossas identidades, de modo que sempre existimos fora de nós mesmos, incapazes de nos concentrar no aqui e agora, aferrados demais à nossa própria imagem, perpetuamente revelando nossa localização atual, nossa privacidade sacrificada à tirania utilitária de uma rede coletiva. ${ }^{38}$

Novamente aqui o problema dos limites normativos do tratamento das informações e da nomeação da realidade, com sua consequente constituição da verdade, aparece com força.

O direito e as mídias sociais, nesse sentido, parecem estar em uma constante disputa intercampos. O poder disruptivo de dupla mão nessa relação é fantástico, tomada em conta a capacidade de nomeação da verdade por um e outro campo. ${ }^{39}$ A dificuldade de se refletir sobre essa intrincada relação não está somente no espaço da disputa política entre os atores dos dois campos, mas também no fato de que a liquidez social de Sigmund Bauman, ou o desencantamento Weberiano com relação às orientações normativas proporcionadas por instituições que cumpriam em dado momento histórico essa função, vem radicalizada por aquilo que se sugere acima como a passagem de um modelo de normas de conduta cujo núcleo doador de sentido eram códigos morais fortes para um modelo de liberdade individual radical que resulta em um outro núcleo doador de sentido, vinculado, em alguns casos, à ideia liberal do pacta sunt servanda. Nesse sentido, não somente a percepção individualista oponível contra todos de obter, em nome do direito à saúde, prestações ilimitadas, mas também, por exemplo, as decisões judiciais sobre união homoafetiva, direito ao nome social e namoro qualificado.

Talvez a saída para o problema da instabilidade normativa gerada por essas características concomitantemente estruturais e conjunturais seja a utilização de certos parâmetros ou, dito de outra forma, de um método qualquer para a produção de decisões sobre questões fundamentais sobre a convivência na comunidade política. Algo, talvez, como a radicalização do uso das instâncias e práticas democráticas como um critério crítico que permita a apreciação dos problemas normativos. ${ }^{40}$ Ao invés de buscar a solução da determinação do que seja o direito à saúde como a identificação de um conteúdo qualquer, a resposta esteja em ampliar os espaços de diálogos interinstitucionais nos quais os conflitos possam ser processados.

É possível, entretanto, que a sugestão encontre limite em um problema conceitual. Se o padrão democrático é atingido por meio de um procedimento não substancializado de busca de consenso, esse método pode resultar em um círculo tautológico, pois busca-se uma norma que presida o próprio processo decisório, mas essa mesma norma pode ter um conteúdo legitimador de injustiça, pois nem sempre o consenso democrático é visto pelo Direito como a melhor solução para uma questão posta ao Poder Judiciário. ${ }^{41}$

É possível pensar, reconhecendo esse impedimento, em um papel contramajoritário com base em uma moral crítica do Direito, no sentido de que essa norma moral não pode ser a da maioria nem a tradicional, mas fundada em uma discussão racional dos fundamentos da escolha, excluídos o impressionismo e os sen-

37 ECO, Umberto. Pape, satàn, aleppe: crônicas de uma sociedade líquida. Rio de Janeiro: Record, 2017. p. 9.

38 KEEN, Andrew. Vertigem digital: por que as redes sociais estão nos dividindo, diminuindo e desorientando. Rio de Janeiro: Zahar, 2012. p. 22

39 BOURDIEU, Pierre. O poder simbólico. Rio de Janeiro: Difel, 1989. cap. VIII

40 CIARLINI, Álvaro L. de A. S. Direito à saúde: paradigmas procedimentais e substanciais da Constituição. São Paulo: Saraiva, 2013. passim.

41 ZAGREBELSKI, Gustavo. A crucificação e a democracia. São Paulo: Saraiva, 2011. 
timentos. ${ }^{42}$ Talvez os limites desse argumento sejam inerentes às possibilidades heurísticas e operatórias do Direito, tanto como campo de reflexão quanto da prática. O incômodo que resulta da tentativa ética de manter as decisões coerentes e isonômicas tendo como necessário o uso da linguagem da moral é constituinte do direito. ${ }^{43}$ Palavras e expressões como dignidade da pessoa humana, interesse social relevante, minimo existencial, são todas avaliatórias e, assim, não permitem estabilidade semântica descritiva anteriormente à contextualização ao caso concreto. ${ }^{44}$

Afinal, parece ter razão Dworkin ao postular que o Direito se situa no campo da moralidade e fora dela não se pode justificar ou fundamentar uma decisão jurídica. Nenhuma dedução de valor se extrai, portanto, como as teorias neohumeanas sustentam, do reconhecimento empírico de fatos. ${ }^{45}$

A reflexão sobre a igualdade e seu papel no direito indica que a doutrina jurídica está sempre fadada a oferecer um rol de topoi a conter a discussão sobre o que significam os objetos e, ao mesmo tempo, entreabrir a necessária ampliação vertical da discussão sobre o impacto da construção da verdade jurídica como igualdade e desigualdade em um ambiente de democracia e de pluralidade de visões normativas em uma sociedade multifacetada, complexa, contraditória e globalizada, em um mundo de valores em permanente conflito.

Por tudo isso, conclui-se que a determinação de deveres jurídicos relativos a direitos de natureza prestacional não pode ser feita no espaço processual de um instrumento de cognição restrita, como é o caso do mandado de segurança, cujas características levam a uma radical limitação da discussão sobre sua definição e extensão.

\section{REFERÊNCIAS}

BARROSO, Luís Roberto. Da falta de efetividade à judicialização excessiva: direito à saúde, fornecimento gratuito de medicamentos e parâmetros para a atuação judicial. In: PEREIRA NETO, Cláudio; SARMENTO, Daniel (Org). Direitos sociais: fundamentos, judicialização e direitos sociais em espécie. Rio de Janeiro: Lumen Juris, 2008.

BARROSO, Luís Roberto. Da falta de efetividade à judicialização excessiva: direito à saúde, fornecimento gratuito de medicamentos e parâmetros para a atuação judicial. In: PEREIRA NETO, Cláudio; SARMENTO, Daniel (Org). Direitos sociais: fundamentos, judicialização e direitos sociais em espécie. Rio de Janeiro: Lumen Juris, 2008.

BAUMAN, Sigmund. Modernidade líquida. Rio de Janeiro: Zahar, 2001.

BOURDIEU, Pierre. O poder simbólico. Rio de Janeiro: Difel, 1989.

BRASIL. Superior Tribunal de Justiça. Recurso especial. REsp 1657156/RJ. Primeira Seção. Rel. Ministro Benedito Gonçalves. Julgado em 25/04/2018, DJe 04/05/2018.

BRASIL. Supremo Tribunal Federal. Ação Direta de Inconstitucionalidade. ADI 5501 MC. Tribunal Pleno. Relator(a): Min. MARCO AURÉLIO. Julgado em 19/05/2016, PROCESSO ELETRÔNICO DJe-168 DIVULG 31-07-2017 PUBLIC 01-08-2017.

\footnotetext{
42 LOPES, José Reinaldo de L. O direito ao reconhecimento para gays e lésbicas. In: GOLIN, Célio (Org.). A justiça e os direitos de gays e lésbicas: jurisprudência comentada. Porto Alegre: Sulina, 2003. p.15.

43 HARE, Richard M. A linguagem da moral. São Paulo: Martins Fontes, 1996.; HARE, Richard M. Moral thinking: its levels, method and point. New York: Oxford University Press, 1981.

44 FREITAS FILHO, Roberto. Decisões jurídicas e teoria linguística: o prescritivismo universal de Richard Hare. Disponível em: <http://www2.senado.leg.br/bdsf/item/id/160456>. Acesso em: 8 de jan. 2018.

45 DWORKIN, Ronald. Justice for hedgehogs. Harvard: Harvard University Press, 2011. p. 5.
} 
BRASIL. Supremo Tribunal Federal. Agravo regimental. STA 175 AgR. Tribunal Pleno. Relator(a): Min. GILMAR MENDES (Presidente. Julgado em 17/03/2010, DJe-076 DIVULG 29-04-2010 PUBLIC 30-042010 EMENT VOL-02399-01 p. 70.

BRASIL. Supremo Tribunal Federal. Pedido de vista adia julgamento sobre acesso a medicamentos de alto custo por via judicial. Disponível em: <http://www.stf.jus.br/portal/cms/verNoticiaDetalhe. asp?idConteudo=326275\&tip=UN>. Acesso em: 6 maio 2018.

BRASIL. Tribunal de Justiça do Distrito Federal e Territórios. Primeira Câmara Cível. Mandado de Segurança. MSG - Mandado de Segurança 2016.00.2.022657-4.

BUCCI, Maria Paula Dallari. O conceito de política pública em direito. In: . (Org.). Políticas públicas: reflexões sobre o conceito jurídico. São Paulo: Saraiva, 2006.

CANOTILHO, J.J. Gomes. Direito constitucional e teoria da constituição. 17. ed. Coimbra: Almedina.

CIARLINI, Álvaro L. de A. S. Direito à saúde: paradigmas procedimentais e substanciais da Constituição. São Paulo: Saraiva, 2013.

COMISSÃO NACIONAL DE INCORPORAÇÃO DE TECNOLOGIAS NO SUS - CONITEC. Ministério da Saúde. Relatório de recomendação: Alfanonacogue - Benefix ${ }^{\circledR}$ para hemofilia B em pacientes menores de 19 anos de idade. Disponível em: <http://conitec.gov.br/images/Consultas/Relatorios/2016/Relatorio_Fator_IX_recomb_CP_39_2016.pdf>. Acesso em: 2 maio 2018.

COMISSÃO NACIONAL DE INCORPORAÇÃO DE TECNOLOGIAS NO SUS - CONITEC. Ministério da Saúde. Fator VIII de origem recombinante para tratamento de pacientes com hemofilia A. Disponível em: <http://conitec.gov.br/images/Incorporados/FatorVIIIRecombinante-final.pdf>. Acesso em: 5 jul. 2018.

DWORKIN, Ronald. A virtude soberana: a teoria e a prática da igualdade. São Paulo: Martins Fontes, 2005.

DWORKIN, Ronald. Justice for hedgehogs. Harvard: Harvard University Press, 2011.

ECO, Umberto. Pape, satàn, aleppe: crônicas de uma sociedade líquida. Rio de Janeiro: Record, 2017.

FEDERAÇÃO MUNDIAL DE HEMOFILIA. Manual para tratamento da hemofilia. Disponível em: <http:// www1.wfh.org/publications/files/pdf-1472.pdf>. Acesso em: 02 maio 2018.

FREITAS FILHO, Roberto. Decisões jurídicas e teoria linguística: o prescritivismo universal de Richard Hare. Disponível em: <http://www2.senado.leg.br/bdsf/item/id/160456>. Acesso em: 8 de jan. 2018.

FREITAS FILHO, Roberto; SILVA, Frederico Augusto Barbosa da. O judiciário cordial, a violência e a corrupção na América Latina. Disponível em: < https://portalrevistas.ucb.br/index.php/REPATS/article/view/8210>. Acesso em: 2 jul. 2018.

FREITAS FILHO, Roberto et al. Políticas públicas e protagonismo judicial no STF: relatório de pesquisa do grupo de estudo e pesquisa em políticas públicas e hermenêutica. Disponível em: <https://www.publicacoesacademicas.uniceub.br/jus/article/view/1503>. Acesso em: 24 jun. 2018.

GARGARELLA, Roberto. As teorias da justiça depois de Rawls: um breve manual de filosofia política. São Paulo: WMF Martins Fontes, 2008.

HARE, Richard M. A linguagem da moral. São Paulo: Martins Fontes, 1996.

HARE, Richard M. Moral thinking: its levels, method and point. New York: Oxford University Press, 1981.

KEEN, Andrew. Vertigem digital: por que as redes sociais estão nos dividindo, diminuindo e desorientando. Rio de Janeiro: Zahar, 2012.

LOPES, José Reinaldo de L. Justiça e poder judiciário ou a virtude confronta a instituição. In: Direitos Sociais: teoria e prática. São Paulo: Método, 2006. 
LOPES, José Reinaldo de L. O direito ao reconhecimento para gays e lésbicas. In: GOLIN, Célio (Org.). $A$ justiça e os direitos de gays e lésbicas: jurisprudência comentada. Porto Alegre: Sulina, 2003.

ORGANIZAÇÃO MUNDIAL DA SAÚDE -OMS. Relatório mundial da saúde 2010: financiamento dos sistemas de saúde. Disponível em: < http://www.who.int/eportuguese/publications/WHR2010.pdf>. Acesso em: 4 maio 2018.

PIKETTY, Thomas. O capital no século XXI. Rio de Janeiro: Intrínseca, 2014.

SABINO, Marco Antonio da Costa. Saúde \& Judiciário: a atuação judicial: limites, excessos e remédios. Curitiba: Juruá, 2016.

SARAVIA, Enrique. Introdução à teoria da política pública. In: FERRAREZI, Elisabete; SARAVIA, Enrique. Políticas públicas: coletânea. Brasília: ENAP, 2006.

SARLET, Ingo W. Comentário ao art. 196. In: CANOTILHO, J. J. Gomes (Coord.) et al. Comentários à constituição do Brasil. São Paulo: Saraiva/Almedina, 2013.

SEN, Amartya. Desigualdade reexaminada. Rio de Janeiro: Record, 2001.

SILVA, Tomaz Tadeu da (Org.) Identidade e diferença: a perspectiva dos estudos culturais. Rio de Janeiro: Vozes, 2009.

WANG, Daniel Wei Liang. Escassez de recursos, custos dos direitos e reserva do possível na jurisprudência do STF. In: SARLET, Ingo Wolfgang; TIMM, Luciano Benetti (Org.). Direitos fundamentais: orçamento e "reserva do possível". 2. ed. Porto Alegre: Livraria do Advogado, 2010.

ZAGREBELSKI, Gustavo. A crucificação e a democracia. São Paulo: Saraiva, 2011. 
Para publicar na revista Brasileira de Políticas Públicas, acesse o endereço eletrônico www.rbpp.uniceub.br

Observe as normas de publicação, para facilitar e agilizar o trabalho de edição. 